\title{
Differential Dynamic Processing of Afferent Signals in Frog Tonic and Phasic Second-Order Vestibular Neurons
}

\author{
Sandra Pfanzelt, ${ }^{1,2}$ Christian Rössert, ${ }^{2}$ Martin Rohregger, ${ }^{3}$ Stefan Glasauer, ${ }^{2}$ Lee E. Moore, ${ }^{1}$ and Hans Straka ${ }^{1}$ \\ ${ }^{1}$ Laboratoire de Neurobiologie des Réseaux Sensorimoteurs, Centre National de la Recherche Scientifique, UMR 7060, Université Paris Descartes, 75270 \\ Paris Cedex 06, France, ${ }^{2}$ Department of Neurology, Bernstein Center for Computational Neuroscience, Ludwig-Maximilians-Universität München, 81377 \\ Munich, Germany, and ${ }^{3}$ Department of Physiology, Ludwig-Maximilians-Universität München, 80336 Munich, Germany
}

The sensory-motor transformation of the large dynamic spectrum of head-motion-related signals occurs in separate vestibulo-ocular pathways. Synaptic responses of tonic and phasic second-order vestibular neurons were recorded in isolated frog brains after stimulation of individual labyrinthine nerve branches with trains of single electrical pulses. The timing of the single pulses was adapted from spike discharge patterns of frog semicircular canal nerve afferents during sinusoidal head rotation. Because each electrical pulse evoked a single spike in afferent fibers, the resulting sequences with sinusoidally modulated intervals and peak frequencies up to $100 \mathrm{~Hz}$ allowed studying the processing of presynaptic afferent inputs with in vivo characteristics in second-order vestibular neurons recorded in vitro in an isolated whole brain. Variation of pulse-train parameters showed that the postsynaptic compound response dynamics differ in the two types of frog vestibular neurons. In tonic neurons, subthreshold compound responses and evoked discharge patterns exhibited relatively linear dynamics and were generally aligned with pulse frequency modulation. In contrast, compound responses of phasic neurons were asymmetric with large leads of subthreshold response peaks and evoked spike discharge relative to stimulus waveform. These nonlinearities were caused by the particular intrinsic properties of phasic vestibular neurons and were facilitated by GABAergic and glycinergic inhibitory inputs from tonic type vestibular interneurons and by cerebellar circuits. Coadapted intrinsic filter and emerging network properties thus form dynamically different neuronal elements that provide the appropriate cellular basis for a parallel processing of linear, tonic, and nonlinear phasic vestibulo-ocular response components in central vestibular neurons.

Key words: semicircular canal; phasic; tonic; afferent fibers; vestibular; macula

\section{Introduction}

Processing of head movement-related signals in vestibulomotor networks occurs in parallel pathways that are organized as frequency-tuned channels from the sensory periphery to the motor plant (Lisberger et al., 1983; Minor et al., 1999; Goldberg, 2000; Straka and Dieringer, 2004). This parallel organization is necessary to transform sensory signals as diverse as static head deviation or high acceleration profiles that occur during rapid locomotion into dynamically adequate motor commands for gaze and posture control. Hair cells in vestibular end organs and vestibular afferent fibers appear to be organized as subpopulations of dynamically different neuronal elements with interrelated morphophysiological properties for the detection and cod-

\footnotetext{
Received July 8, 2008; revised Aug. 22, 2008; accepted Aug. 28, 2008.

This work was supported by the French (entre National de la Recherche Scientifique and (entre National d'Etudes Spatiales. S.P. received funding from a Marie-Curie Training Sites contract HPMT-CT-2000-00008 (France), the Deutscher Akademischer Austauschdienst D/05/40377 (Germany), and the Graduiertenkolleg 1091 (Orientation and Motion in Space); (.R. received a PhD grant from the Bayerische Forschungsstiftung. We thank Dr. Mathieu Beraneck for critically reading this manuscript and Dr. Isabelle Vassias for excellent processing and photographing of the histological material shown in Figure $2 \mathrm{~A}$.

Correspondence should be addressed to Dr. Hans Straka, Laboratoire de Neurobiologie des Réseaux Sensorimoteurs, Centre National de la Recherche Scientifique, UMR 7060, Université Paris Descartes, 45 rue des Saints-Pères, 75270 Paris Cedex 06, France. E-mail: hans.straka@univ-paris5.fr.

D0I:10.1523/JNEUROSCI.3368-08.2008

Copyright $\odot 2008$ Society for Neuroscience ～0270-6474/08/2810349-14\$15.00/0
}

ing of head motion (Baird, 1994a,b; Eatock et al., 1998; Goldberg, 2000; Straka and Dieringer, 2004).

At the level of central vestibular neurons distinct subpopulations of second-order vestibular neurons $\left(2^{\circ} \mathrm{VNs}\right)$ with different intrinsic membrane properties have been observed in various vertebrate species (Serafin et al., 1991; Johnston et al., 1994; du Lac and Lisberger, 1995; Peusner and Giaume, 1997; Straka et al., 2005). Although cellular properties of $2^{\circ} \mathrm{VNs}$ may vary between vertebrate species, the different neuronal subgroups form specific filter elements, respectively (Straka et al., 2005). If appropriately adapted to the dynamics of the sensory afferent inputs, these central vestibular populations could separately mediate linear (tonic) and nonlinear (phasic) vestibulomotor components (Minor et al., 1999; Clendaniel et al., 2002).

Based on specific differences in intrinsic membrane properties, frog $2^{\circ} \mathrm{VNs}$ subdivide into two distinct neuronal subtypes (Straka et al., 2004; Beraneck et al., 2007). Tonic $2^{\circ} \mathrm{VNs}$ behave like low-pass filters, whereas phasic $2^{\circ} \mathrm{VNs}$ show a pronounced resonance behavior for subthreshold membrane polarization and spike discharge, thereby generating potential-dependent bandpass filters (Beraneck et al., 2007). The different impedance behavior during membrane polarization makes the two subtypes most suitable for amplification (tonic $2^{\circ} \mathrm{VNs}$ ) and differentiation (phasic $2^{\circ} \mathrm{VNs}$ ) of vestibular inputs (Beraneck et al., 2007). A different insertion of the two neuronal subtypes into local inhib- 
itory networks as indicated by the presence of ipsilateral disynaptic feedforward IPSPs in phasic but not tonic $2^{\circ} \mathrm{VNs}$ (Biesdorf et al., 2008) concurs with the highly transient intrinsic properties of the former neurons. The distinctly different filter properties and their differential effect on single monosynaptic afferent EPSPs in phasic and tonic $2^{\circ} \mathrm{VNs}$ suggests that more complex synaptic inputs similar to those that occur during natural head movements would be the appropriate test to reveal the different modes of signal processing of the two subtypes.

The present study uses the isolated brain of adult frogs to investigate the synaptic responses of tonic and phasic $2^{\circ} \mathrm{VNs}$ after activation of labyrinthine nerve afferents by trains of single electrical pulses with a timing that was obtained from the spike discharge of afferent fibers during head movements. For this purpose, the spike activity of frog vestibular nerve afferents during sinusoidal head rotation in vivo (Blanks and Precht, 1976) was transformed into a sequence of single electrical pulses for the activation of individual labyrinthine nerve branches in vitro.

Preliminary results have been published previously in abstract form (Pfanzelt et al., 2004).

\section{Materials and Methods}

In vitro experiments were performed on the isolated brains of 47 grass frogs (Rana temporaria) and complied with the Principles of Animal Care (publication No. 86-23, revised in 1985 by the National Institutes of Health). Permission for these experiments was granted by the government of Oberbayern (211-2531-31/95). As described in previous studies (Straka and Dieringer, 1993), the animals were deeply anesthetized with $0.1 \%$ MS-222 (3-aminobenzoic acid ethyl ester), and perfused transcardially with iced Ringer's solution [(in mM) $75 \mathrm{NaCl}, 25 \mathrm{NaHCO}_{3}, 2$ $\mathrm{CaCl}_{2}, 2 \mathrm{KCl}, 0.5 \mathrm{MgCl}_{2}, 11$ glucose, $\mathrm{pH}$ 7.4]. Thereafter, the skull and bony labyrinth were opened by a ventral approach. After dissecting the three semicircular canals on each side, the brain was removed with all labyrinthine end organs attached to the eighth nerve. Subsequently, the brain was submerged in iced Ringer's and the dura, the labyrinthine end organs, and the choroid plexus covering the fourth ventricle were removed. In all experiments, the forebrain was removed. Brains were used up to $4 \mathrm{~d}$ after their isolation and were stored overnight at $6^{\circ} \mathrm{C}$ in continuously oxygenated Ringer's solution (carbogen, $95 \% \mathrm{O}_{2}, 5 \% \mathrm{CO}_{2}$ ) with a $\mathrm{pH}$ of $7.5 \pm 0.1$. For the experiments, the brainstem was glued with cyanoacrylate to a plastic mesh, which was fixed with insect pins to the Sylgard floor of a chamber (volume, $2.4 \mathrm{ml}$ ). The chamber was continuously perfused with oxygenated Ringer's solution at a rate of 1.3-2.1 $\mathrm{ml} / \mathrm{min}$. The temperature was electronically controlled and maintained at $14 \pm 0.1^{\circ} \mathrm{C}$.

Intracellular recordings were obtained from vestibular nerve afferent fibers $(n=27)$ and central vestibular neurons $(n=110)$. Vestibular nerve afferents were recorded in the eighth nerve between Scarpa's ganglion and the entry of the nerve into the brainstem. The peripheral origin of individual afferent fibers was determined by the presence of shortlatency all-or-nothing antidromic responses $(<0.8 \mathrm{~ms})$ after separate electrical stimulation of the three semicircular canal nerves or the lagenar nerve branch. Central neurons in the vestibular nuclei were identified as $2^{\circ} \mathrm{VNs}$ by their monosynaptic responses to separate stimulation of the nerve branches. For electrical activation of the nerve branches, single constant current pulses (duration, $0.2 \mathrm{~ms}$; threshold, 1.5-3.1 $\mu \mathrm{A}$ ) were applied across individually adjusted suction electrodes (diameter, 120 $150 \mu \mathrm{m}$ ). The use of this electrode type facilitated the isolation of the individual nerve branches without current spread to other labyrinthine nerve branches. Pulses were produced by a stimulus isolation unit (World Precision Instruments A 360).

Glass microelectrodes used for extracellular and intracellular recordings were made with a horizontal puller (P-87 Brown/Flaming). Electrodes for extracellular field potential recordings were beveled $\left(30^{\circ}, \sim 20\right.$ $\mu \mathrm{m}$ tip diameter) and filled with a $2 \mathrm{M}$ solution of sodium chloride $(\sim 1$ $\mathrm{M} \Omega$ final resistance). Electrodes for intracellular recordings were filled with a mixture of $2 \mathrm{~m}$ potassium acetate and $3 \mathrm{~m}$ potassium chloride
(10:1), which gave a final resistance of $\sim 90-110 \mathrm{M} \Omega$. Neuronal recordings were made in bridge mode (SEC-05L; NPI Electronic).

At the beginning of each experiment, presynaptic and postsynaptic field potentials evoked by separate stimulation of the labyrinthine nerve branches were recorded at a standard reference site in the vestibular nuclei to optimize the position of the stimulus electrodes and to determine the stimulus threshold $(T)$ for each nerve branch (Straka et al., 1997, 2002). Stimulus intensities were indicated as multiples of the threshold values for the postsynaptic field potentials. Vestibular neurons were recorded in all vestibular subnuclei (lateral, superior, descending, and medial), except the most medial parts of the medial vestibular nucleus. Based on the differential discharge patterns during long positive current steps, frog $2^{\circ} \mathrm{VNs}$ were distinctly distinguished into phasic or tonic vestibular neurons (Straka et al., 2004; Beraneck et al., 2007). As reported previously, most of the vestibular neurons in the isolated frog brain had no spontaneous discharge at resting membrane potential (Straka and Dieringer, 2004; Straka et al., 2005). Only neurons with a membrane potential more negative than $-55 \mathrm{mV}$ were included in this study.

A differential processing of synaptic signals in phasic and tonic type $2^{\circ} \mathrm{VNs}$ was studied by applying stimulus trains of single current pulses to the labyrinthine nerve branch, which were as close as possible to naturally occurring vestibular afferent input patterns. The trains consisted of individual pulses with interstimulus frequencies that were sinusoidally modulated up to a variable maximal frequency. The timing of the single pulses in the train and the maximal peak frequency was obtained from the discharge pattern of frog horizontal canal afferent fibers during sinusoidal vertical axis rotation (see Fig. 1A) (Blanks and Precht, 1976). The imitation of a natural vestibular afferent discharge by an electrical stimulus train applied to labyrinthine nerve branches in the isolated whole brain in vitro is an approximation and restricted by differences in the synchronicity of the evoked discharge in the population of recruited afferent fibers and the activated fiber spectrum compared with the in vivo situation. However, this particular stimulus paradigm provides an excellent way to bridge the gap between in vivo studies of vestibulo-ocular functionality and in vitro single-cell studies of intrinsic membrane properties of $2^{\circ} \mathrm{VNs}$

For the transformation of the afferent activity in vivo into a stimulus train, the discharge of an afferent fiber to sinusoidal head acceleration at $0.2 \mathrm{~Hz}\left( \pm 20^{\circ}\right)$ was fitted with a sine wave function (see Fig. $1 A_{1}$ ). Because the resting discharge of this as of most other vestibular nerve afferent fibers in frog is very low $(<2-10$ spikes/s) (Blanks and Precht, 1976; Dieringer and Precht, 1977), the sine wave was only fitted for the activation half cycle. This sine wave function was transformed into a sequence of single events with sinusoidally modulated intervals and peak frequencies of 40,70,100,150, or $200 \mathrm{~Hz}$ for different sets of experiments (see Fig. $1 A_{2}$ ). This sequence was applied during the first half cycle of a sine wave and was followed by a second half cycle without stimuli (see Fig. $\left.1 A_{3}\right)$. These electrical pulse trains were applied multiple times $(8-20$ cycles) to those semicircular canal or the lagena nerve branches that were monosynaptically connected to the recorded $2^{\circ} \mathrm{VNs}$. In the following, this stimulation will be denoted as "sinusoidal pulse train."

Each single pulse generated one spike in afferent fibers and evoked monosynaptic EPSPs in $2^{\circ} \mathrm{VNs}$. Synaptic compound responses in phasic and tonic $2^{\circ} \mathrm{VNs}$ were formed by the temporal summation of the evoked individual monosynaptic EPSPs. These compound responses were characterized by several stimulus parameters, such as stimulus peak frequency $(40,70$, or $100 \mathrm{~Hz})$, half-cycle length $(0.25,0.5,1$, or $2.5 \mathrm{~s})$, and single-pulse intensity $(1.2$ to $5 \times T)$. Amplitude and timing of the evoked responses were quantified in smoothed fits of the compound responses (see Fig. 2D, E, red lines). A compound response peak advance (+) or lag $(-)$ relative to stimulus peak frequency was determined as the time between compound response peak and stimulus peak frequency and converted into degrees. The conversion allowed comparing the results obtained at different half-cycle lengths.

A contribution of glycinergic and GABAergic inhibitory circuits to the processing of synaptic signals in $2^{\circ} \mathrm{VNs}$ was studied by bath application of strychnine (Sigma; $1 \mu \mathrm{M}$ ) and bicuculline (Sigma; $1-5 \mu \mathrm{M}$ ). Surgical removal of the cerebellum or pressure injection of 100-150 $\mathrm{nl}$ of lidocaine (Sigma; $2-5 \%$ in Ringer's solution) through a beveled injection 
electrode $\left(30^{\circ}, 10-15 \mu \mathrm{m}\right.$ tip diameter) into the ipsilateral cerebellar peduncle was used to reveal a contribution of the cerebellum to the processing of afferent signals in $2^{\circ} \mathrm{VNs}$.

Single sweeps of the responses were digitized (CED 1401; Cambridge Electronic Design), stored on computer, and analyzed off-line (Signal, Cambridge Electronic Design; and Matlab, MathWorks). Synaptic potentials were analyzed from averages of 8-20 single sweeps after electronic subtraction of the extracellular field potential recorded in the vicinity. Statistical differences in parameters were calculated according to the Mann-Whitney $U$ test (unpaired parameters) and the Wilcoxon signed rank test (paired parameters; Prism, Graphpad Software). All averaged results are expressed as mean $\pm \mathrm{SE}$. Graphical presentations were made with the aid of commercially available computer software (Origin, Microcal Software; Corel Draw, Corel).

Retrograde labeling of vestibular projection neurons and anterograde tracing of vestibular nerve afferent fibers (see Fig. $2 \mathrm{~A}$ ) helped to determine the location of neurons within the vestibular nuclear boundary in the isolated frog brain based on external landmarks. To outline the location of central vestibular neurons and the termination of vestibular nerve afferent fibers, crystals of Alexa Fluor 488 (green) or 546 dextran (red) were inserted unilaterally into the oculomotor nucleus or the upper spinal cord, or were placed on particular vestibular nerve branches in the periphery in isolated frog brains in vitro. After $48 \mathrm{~h}$ of survival at $9^{\circ} \mathrm{C}$, brains were fixed in $4 \%$ paraformaldehyde in $0.1 \mathrm{~m}$ phosphate buffer (PB) for $24 \mathrm{~h}$ and stored overnight in 15 and $30 \%$ sucrose in $0.1 \mathrm{M} \mathrm{PB}$. All brains were cut transversally in $60 \mu \mathrm{m}$ sections on a cryostat. Sections were mounted on slides, coverslipped with Vectashield (Vector Laboratories; Biovalley), and analyzed by laser scanning confocal microscopy (Zeiss LSM 510) at a wavelength of 488 or $543 \mathrm{~nm}$. Stacks of 10-20 confocal images were generated with a $20 \times / 0.5$ objective and a plan Apochromat $40 \times / 1.3$ oil-immersion objective. Images for Figure $2 \mathrm{~A}$ were produced by horizontal projection of the entire stack.

Modeling of the synaptic processing in tonic and phasic $2^{\circ} \mathrm{VNs}$ was performed by extending previously described intrinsic neuronal models (Borg-Graham, 1991; Moore et al., 1995) with conductance-based synapses. Parameter estimation was based on frequency responses of representative phasic and tonic $2^{\circ} \mathrm{VNs}$ (Beraneck et al., 2007). The estimation was done by a compartmental admittance formulation, which consisted of an active soma and one active dendrite with three compartments. All passive and active parameters were assumed to be uniformly distributed (Moore et al., 1995; Murphey et al., 1995). Parameters were estimated using a compartmental admittance formulation in Matlab (MathWorks). Real-time compartmental models were simulated in NEURON (Carnevale and Hines, 2006) (for a detailed description, see the supplemental material, available at www.jneurosci.org).

Dual-exponential conductance-based synapses were added to the intrinsic single-cell compartmental models using the following equation: $I_{\mathrm{sb}}=g_{\mathrm{sb}} F\left[\exp \left(-t / \tau_{2}\right)-\exp \left(-t / \tau_{1}\right)\right]\left(V_{i}-V_{\mathrm{sb}}\right)$ with $\tau_{1}$ as rise and $\tau_{2}$ as fall time constant (Johnston and $\mathrm{Wu}, 1994)$. The peak conductance for a single synaptic event was defined by $g_{\mathrm{sb}} ; V_{\mathrm{sb}}$ indicates the reversal potential and $V_{i}$ the current compartmental membrane potential. The scaling factor $F$ is defined such that the peak of the dual exponential is 1 . These synapses were implemented by the function "exp2syn" in the NEURON simulation environment, extended by an absolute synaptic refractory period (Hjelmstad et al., 1997). The values of the reversal potentials for excitatory $\left(V_{\mathrm{sE}}=0 \mathrm{mV}\right)$ and inhibitory synapses $\left(V_{\mathrm{sI}}=-75 \mathrm{mV}\right)$ were obtained from Hille (2001). Two different parameter sets for synaptic innervation were used: the "E compartmental model" consisted of one excitatory synapse at the last dendritic compartment with the following parameters: $\tau_{1}=5 \mathrm{~ms}, \tau_{2}=97 \mathrm{~ms}, g_{\mathrm{sE}}=16.8 \mathrm{nS}$. To mimic the monosynaptic excitation, a delay of $3.4 \mathrm{~ms}$ (Biesdorf et al., 2008) from the stimulus to the onset of the excitation was used. For the "E/I compartmental model" the $E$ compartmental model was extended by two inhibitory synapses at the soma: glycine $\left(\tau_{1}=2 \mathrm{~ms}, \tau_{2}=200 \mathrm{~ms}, g_{\mathrm{sI}}=22.5 \mathrm{nS}\right)$ and $\mathrm{GABA}_{\mathrm{A}}\left(\tau_{1}=2 \mathrm{~ms}, \tau_{2}=91 \mathrm{~ms}, g_{\mathrm{sI}}=16.8 \mathrm{nS}\right)$. All synaptic time constants and conductances were obtained by fitting published experimental data (Biesdorf et al., 2008). The inhibition for the stimulation paradigms $70 \mathrm{~Hz} / 2.5 \mathrm{~s}$ (peak frequency/half-cycle length) in the model was activated by detected spike events of phasic or tonic neurons, using a synaptic delay of $1.8 \mathrm{~ms}$ (Straka et al. 1997). For all other computations, the spike discharge of tonic $2^{\circ} \mathrm{VNs}$ has been generated from the $70 \mathrm{~Hz} / 2.5$ $\mathrm{s}$ stimulation paradigm.

\section{Results}

\section{Discharge of vestibular nerve afferent fibers}

Vestibular nerve afferent fibers $(n=27)$ during sinusoidal pulsetrain stimulation of individual labyrinthine nerve branches (Fig. $1 A_{3}$ ) were recorded intracellularly to determine the maximal peak frequency at which each single pulse in the train was still able to evoke spikes. Recorded afferent fibers originated from the horizontal canal ( $\mathrm{HC} ; n=4)$, the anterior vertical canal $(\mathrm{AC} ; n=4)$, the posterior vertical canal (PC; $n=12$ ), or the lagena (LA; $n=$ 7). Spikes were elicited by electrical pulse intensities between $\sim 1.2$ and $3 \times T$ of the afferent nerve-evoked field potential recorded in the vestibular nuclei (threshold, 1.5-3.1 $\mu \mathrm{A}$ ). All pulses of the stimulus train evoked single spikes up to a peak frequency of $\sim 100 \mathrm{~Hz}$ (Fig. $1 B_{1}, B_{2}, C$, inset for 40 and $100 \mathrm{~Hz}$ ). Because each individual pulse evoked only one spike, the discharge in the afferent fibers had the same frequency modulation as the stimulus train. At a higher peak frequency, increasingly more single pulses of the train failed to evoke spikes (Fig. $1 B_{3}, C$, inset for $200 \mathrm{~Hz}$ ). Although some fibers responded with an action potential to each single pulse up to peak frequencies of $150 \mathrm{~Hz}$, the discharge reliability of the population of recorded afferent neurons decreased progressively for stimulus trains with peak frequencies $>100 \mathrm{~Hz}$ (Fig. 1C).

Because intracellular recordings of axons were likely biased toward larger fibers, the upper frequency for reliable firing during pulse trains are likely dominated by the results from the thickest vestibular nerve afferents. However, the amplitude of labyrinthine nerve-evoked presynaptic field potentials in the vestibular nuclei remained unchanged for stimulus frequencies up to 100 $\mathrm{Hz}$ in vitro (Biesdorf and Straka, 2004), indicating that most afferents can sustain a discharge up to this frequency, compatible with in vivo data (Blanks and Precht, 1976). Therefore, the maximal stimulus peak frequency was limited to $100 \mathrm{~Hz}$ in the present study to assure the faithful activation of spikes in all afferent fibers by each electrical pulse of the stimulus train. Because afferent fibers in our in vitro study were silent at rest, this electrical stimulus generated a defined presynaptic activity pattern in all afferents that terminate on a particular vestibular neuron. Thus, this electrical stimulus paradigm, which is based on the timing of the spike discharge of a vestibular nerve afferent fiber during a head movement in vivo, is well suited to reveal the dynamic processing of vestibular sensory signals in the different neuronal subtypes. Because frog phasic and tonic vestibular neurons receive monosynaptic inputs from a similar afferent fiber spectrum (Straka et al., 2004) any differences in the dynamics of the synaptic processing are unlikely to result from different afferent termination patterns on the two neuronal subtypes, but rather are caused by differences in intrinsic membrane and/or emerging network properties.

\section{Identification and classification of frog vestibular neurons}

Central vestibular neurons $(n=110)$ were recorded in the isolated frog brain throughout the rostrocaudal extent of the vestibular nuclei. Retrogradely labeled vestibulo-ocular (Fig. $2 A_{1}, A_{2}$ ) and vestibulospinal neurons after application of Alexa Fluor 546 dextran in the oculomotor nucleus, or the upper spinal cord and the labeled terminal field of vestibular nerve afferent fibers (Fig. $2 \mathrm{~A}_{3}$ ) outlined the location of the vestibular neurons in the dorsal hindbrain. Data on afferent and efferent vestibular connections 

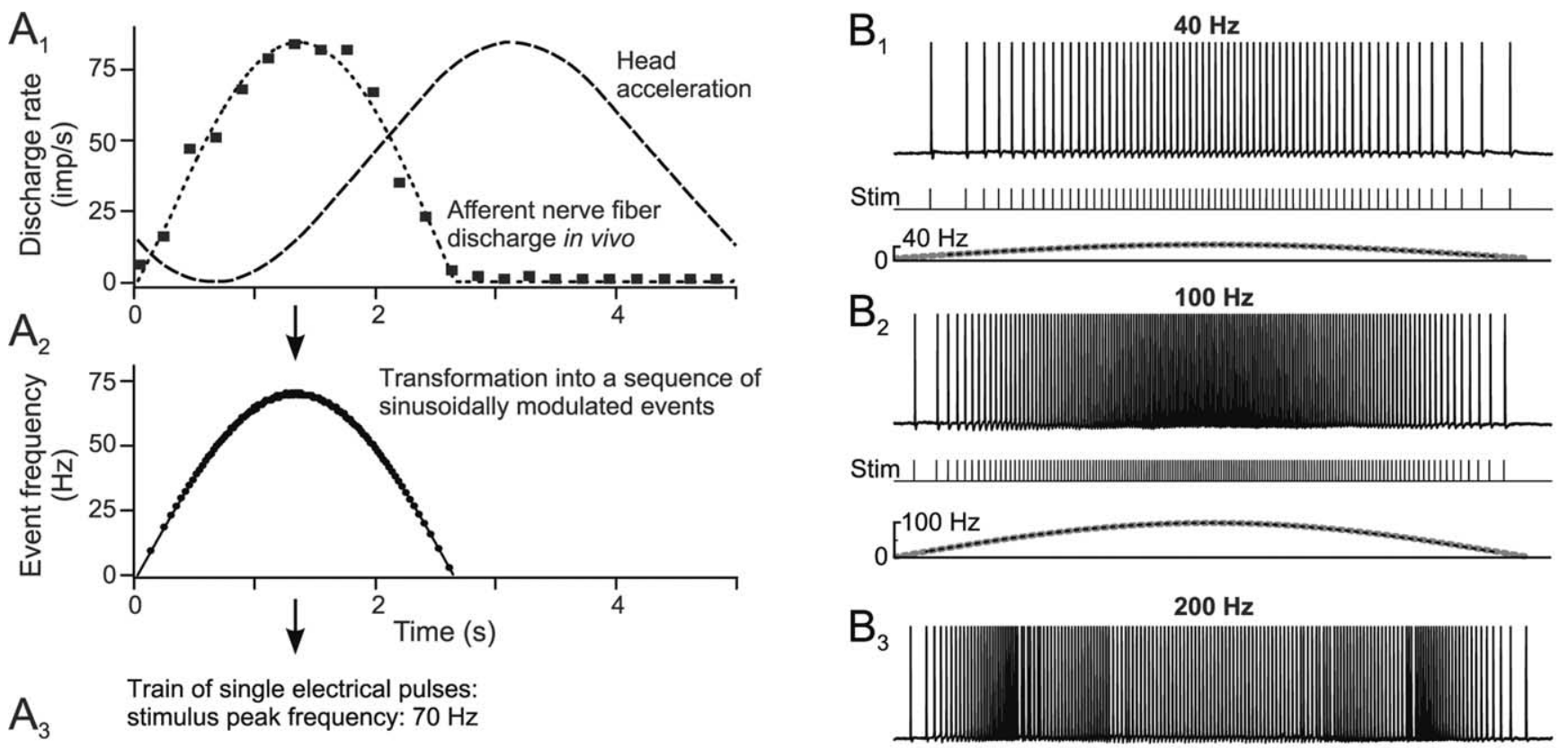

$\mathrm{A}_{3} \quad \begin{aligned} & \text { Train of single electrical pulses: } \\ & \text { stimulus peak frequency: } 70 \mathrm{~Hz}\end{aligned}$
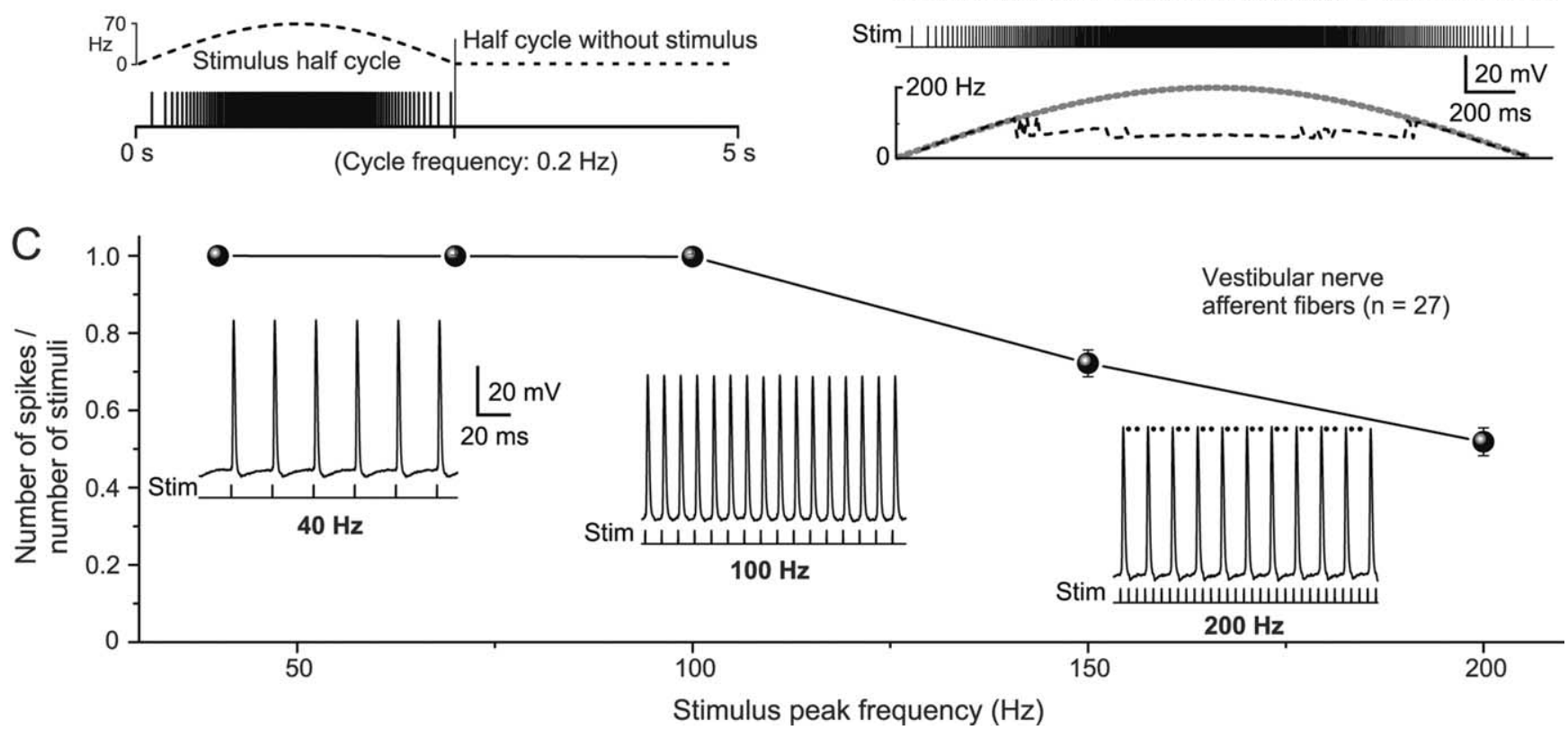

Figure 1. Discharge of vestibular nerve afferent fibers evoked by trains of single electrical pulses (sinusoidal pulse train). $A_{1}-A_{3}$, The discharge of a horizontal semicircular canal afferent fiber ( $\square$ ) recorded during a $0.2 \mathrm{~Hz}\left( \pm 20^{\circ}\right)$ sinusoidal rotation in frog in vivo (Blanks and Precht, 1976) was fitted with a sine wave function (dashed line in $A_{1}$ ), transformed into sinusoidally modulated sequences of events with modifiable peak frequencies $\left(\boldsymbol{A}_{2}, \boldsymbol{O}\right)$, and used as a template for pulse trains to electrically stimulate individual labyrinthine nerve branches $\left(\boldsymbol{A}_{3}\right)$. Because of the low resting discharge, only one half cycle was used for stimulation. $\boldsymbol{B}_{1}-\boldsymbol{B}_{3}$, Intracellular recorded spike discharge of a posterior vertical canal afferent fiber evoked by a sinusoidal pulse train (Stim) with peak frequencies of $40\left(\boldsymbol{B}_{1}\right), 100\left(\boldsymbol{B}_{2}\right)$, and $200 \mathrm{~Hz}\left(\boldsymbol{B}_{3}\right)$; bottom traces in $\boldsymbol{B}_{1}-\boldsymbol{B}_{3}$ indicate pulse trains, stimulus frequency (dotted gray line), and discharge rate (dashed black line). The calibration in $\boldsymbol{B}_{3}$ also applies to $\boldsymbol{B}_{1}$ and $\boldsymbol{B}_{2}$. $\boldsymbol{C}$, Ratio between the number of spikes and stimulus pulses (mean $\pm \mathrm{SE}$ ) as a function of peak frequency (1 indicates that each single pulse of a train evokes one single spike). Insets, Spike discharge of the afferent fiber shown in $\boldsymbol{B}_{1}-\boldsymbol{B}_{3}$ at peak frequencies of 40,100 , and $200 \mathrm{~Hz}$ at an extended time scale; at a peak frequency of $200 \mathrm{~Hz}$, two of three stimuli failed to evoke spikes (black dots). The calibration for the trace at $40 \mathrm{~Hz}$ applies to all insets.

(Straka and Dieringer, 1991; Birinyi et al., 2001), as well as the location of vestibular projection neurons and the termination of vestibular nerve afferent fibers relative to external landmarks (e.g., entry of the eighth nerve into the brainstem; dorsal apex), served as clues for localizing the recording area for $2^{\circ} \mathrm{VNs}$ in the isolated frog brain.

Based on intrinsic membrane properties and discharge behavior in response to intracellular current injection, central VNs were classified as phasic or tonic neurons (Straka et al., 2004). As described previously, during injection of long positive current steps, tonic VNs ( $n=15 ; 13.6 \%)$ exhibited a continuous discharge throughout the current step (Fig. 2B) (Straka et al., 2004; Beraneck et al., 2007). In contrast, the larger population of phasic VNs $(n=95 ; 86.4 \%)$ responded with a short, high-frequency burst of one to three spikes within the first $50 \mathrm{~ms}$ (Fig. 2C), which unequivocally separated these neurons from tonic VNs. The difference in the evoked discharge pattern was paralleled by a significant difference ( $p \leq 0.0001$; Mann-Whitney $U$ test) in the input resistance between phasic $(11.8 \pm 3.1 \mathrm{M} \Omega ; n=42)$ and tonic neurons $(21.5 \pm 3.9 \mathrm{M} \Omega ; n=11)$. In contrast, the resting mem- 


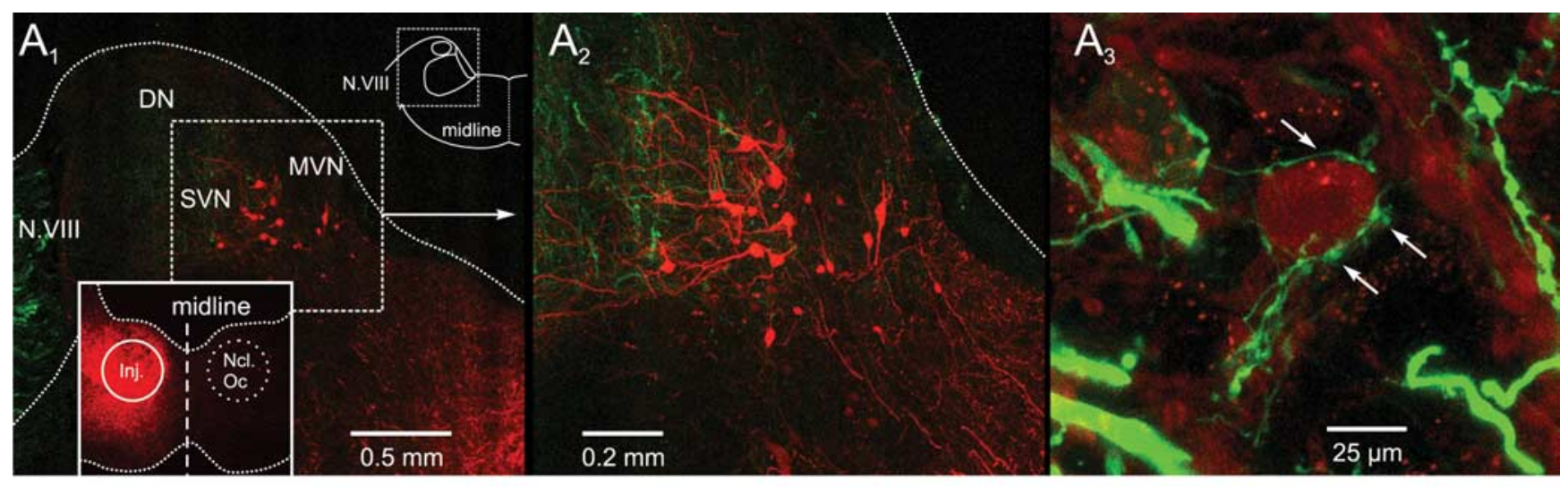

Tonic $2^{\circ} \mathrm{VN}$

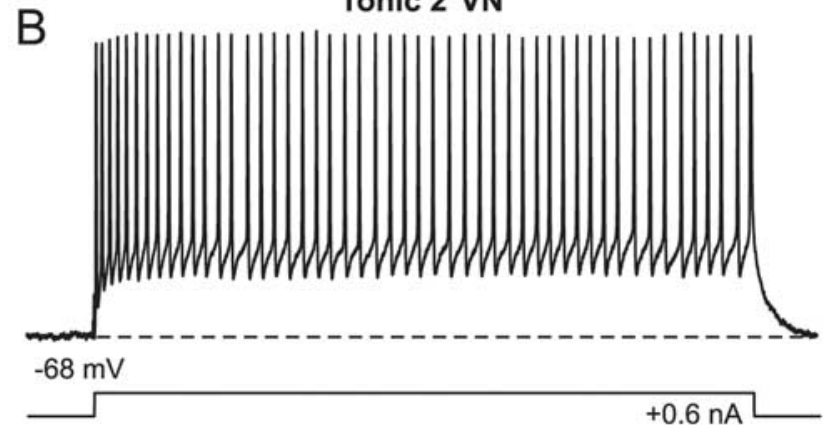

$\mathrm{D}$

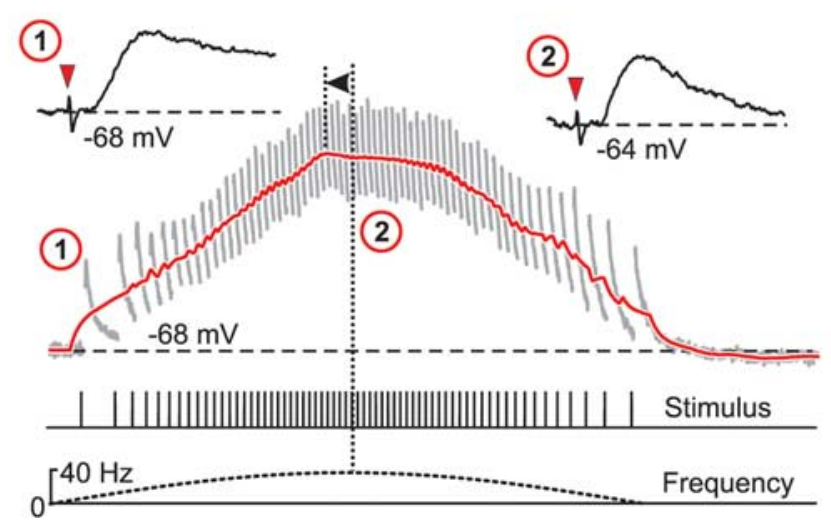

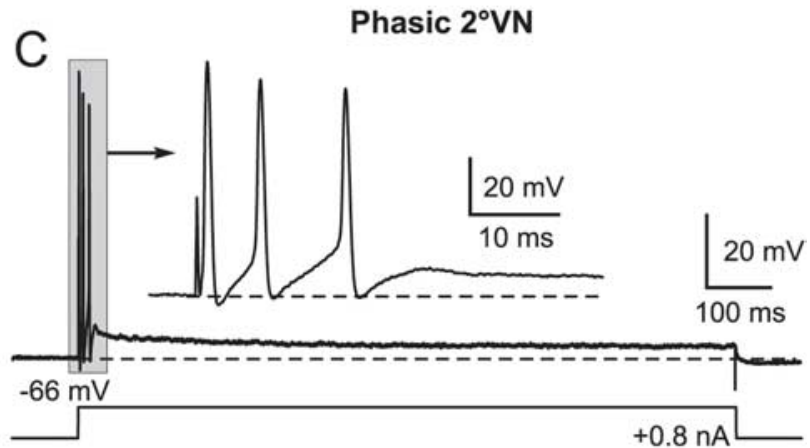

E

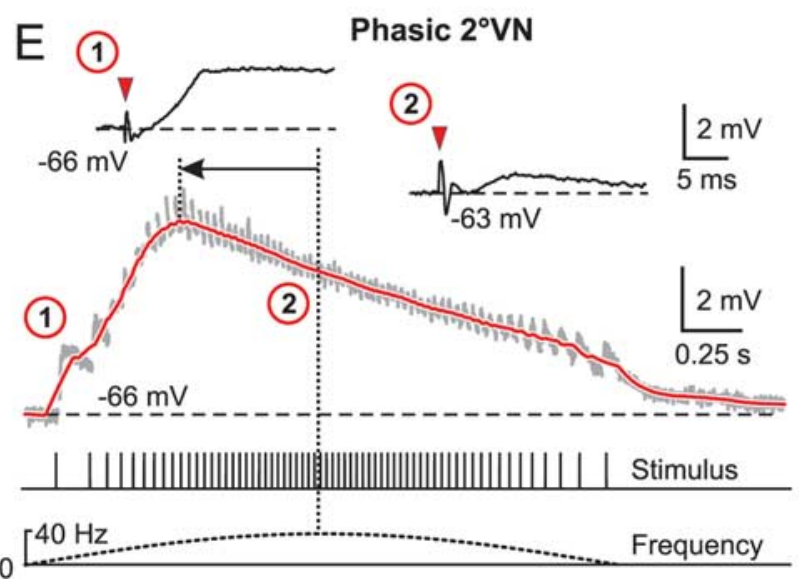

Figure 2. Synaptic compound responses evoked by pulse-train stimulation of semicircular canal nerves in identified central vestibular neurons. $\boldsymbol{A}_{\boldsymbol{1}}$, The location of retrogradely labeled vestibulo-ocular neurons in the superior vestibular nucleus (SVN) and MVN after injection of Alexa Fluor 546 dextran (red) into the ipsilateral oculomotor nucleus (Ncl 0 c; inset) help determine the area for the recordings in the isolated frog brain. $A_{2}$, Higher magnification of labeled $S V N$ and $M V N$ vestibulo-ocular neurons located in the outlined area in $A_{1} . A_{3}, A C$ afferent fibers, labeled in green from the periphery with Alexa Fluor 488 dextran, contact the soma (arrows) of a neuron in the SVN. $\boldsymbol{B}, \boldsymbol{C}, A$ continuous discharge $(\boldsymbol{B})$ and a short burst of three spikes $(\boldsymbol{C})$ evoked by intracellular injection of long positive current steps (bottom traces) characterized tonic $(\boldsymbol{B})$ and phasic $2^{\circ} \mathrm{VNs}(\boldsymbol{C})$, respectively. The inset in $\boldsymbol{C}$ shows the short initial burst (gray area) of the phasic $2^{\circ} \mathrm{VN}$ at an extended time scale. $\boldsymbol{D}, \boldsymbol{E}$, Compound responses formed by temporal summation of individual EPSPs (gray traces) after pulse-train stimulation of the $\mathrm{AC}$ nerve with a peak frequency of $40 \mathrm{~Hz}$ in the same tonic $(\boldsymbol{D})$ and phasic $2^{\circ} \mathrm{VN}(\boldsymbol{E})$ as shown in $\boldsymbol{B}$ and $\boldsymbol{C}$, respectively. The bottom traces indicate pulse train and stimulus frequency. Insets in $\boldsymbol{D}$ and $\boldsymbol{E}$ show EPSPs evoked by the first single pulse of the train (1) and by the single pulse at peak frequency (2) at an extended time scale; horizontal dashed lines in $\boldsymbol{B}-\boldsymbol{E}$ indicate the membrane potential $(-68 \mathrm{mV}$ in $\boldsymbol{B}, \boldsymbol{D} ;-66 \mathrm{mV}$ in $\boldsymbol{C}, \boldsymbol{E})$. Red arrowheads in insets in $\boldsymbol{D}$ and $\boldsymbol{E}$ indicate the single pulses. Red traces in $\boldsymbol{D}$ and $\boldsymbol{E}$ are smoothed fits of the compound responses; horizontal arrows indicate the advance of the compound response peak with respect to stimulus peak frequency (vertical dotted lines). Records in $\boldsymbol{B}$ and $\boldsymbol{C}$ are single sweeps, and in $\boldsymbol{D}$ and $\boldsymbol{E}$ are the average of 12 responses. Calibrations in $\boldsymbol{C}$ and $\boldsymbol{E}$ apply to $\boldsymbol{B}$ and $\boldsymbol{D}$, respectively. DN, Dorsal auditory nucleus.

brane potential of the two subtypes were similar (phasic, $-68.4 \pm$ $12.3 \mathrm{mV}, n=95$; tonic, $-69.2 \pm 9.2 \mathrm{mV}, n=15$ ).

Recorded neurons in the vestibular nuclei were identified as second-order by an EPSP with a monosynaptic onset after electrical stimulation of a particular ipsilateral semicircular canal or the lagenar nerve (Fig. 2D, E, inset 1). This monosynaptic EPSP is the physiological correlate of the morphologically visualized synaptic connection between vestibular nerve afferent fibers and central vestibular neurons (Fig. $2 A_{3}$, arrows). The criteria for the timing of monosynaptic responses have been described previously in detail (Straka and Dieringer, 1997). Accordingly, semicircular canal or lagenar nerve-evoked EPSPs with onset latencies between 2.7 and $4.5 \mathrm{~ms}$ were considered as monosynaptic. Based on this definition, the recorded $2^{\circ} \mathrm{VNs}$ could be distinguished as $2^{\circ} \mathrm{HC}(n=28), 2^{\circ} \mathrm{AC}(n=32), 2^{\circ} \mathrm{PC}(n=33)$ and $2^{\circ} \mathrm{LA}(n=17)$ neurons. Although many of these neurons received, in addition, 
inputs with disynaptic or oligosynaptic latencies from one or more ipsilateral labyrinthine nerve branches, only the monosynaptic inputs were considered for further investigation.

\section{Activation of second-order vestibular neurons with sinusoidal pulse trains}

The responses of tonic and phasic $2^{\circ} \mathrm{VNs}$ to electrical stimulation of a particular vestibular nerve branch with a sinusoidal pulse train consisted of a temporal summation of the individual monosynaptic EPSPs evoked by each single pulse (Fig. $2 D, E$, gray traces). In tonic $2^{\circ} \mathrm{VNs}(n=14)$, compound responses were rather symmetric with a slow rise and decay and an overall waveform that was approximately aligned with the stimulus frequency modulation (Fig. 2D, compare red solid and dashed lines below stimulus). Thus, the compound response peak in this neuronal type (Fig. $2 D$, vertical dotted lines, horizontal arrow) approximately matched the stimulus peak frequency or was slightly advanced (Fig. $2 D$, vertical dotted lines, arrowhead). In contrast, phasic $2^{\circ} \mathrm{VNs}(n=67)$ showed a relatively rapid rise and an early decay of the compound response that created a considerable peak advance (Fig. $2 E$, vertical dotted lines, horizontal arrow) relative to the stimulus peak frequency (Fig. 2E, compare red solid and dashed lines below stimulus). This pronounced difference in compound response dynamics and response peak timing relative to stimulus waveform of tonic and phasic $2^{\circ} \mathrm{VNs}$ was characteristic and suggested a different postsynaptic signal processing in the two neuronal subtypes.

The different dynamics of compound responses in tonic and phasic $2^{\circ} \mathrm{VNs}$ were paralleled by differences in the behavior of the individual monosynaptic EPSPs during the pulse train (Fig. $2 D, E$, insets 1,2$)$. Compared with the first EPSP, the amplitudes of those evoked by the subsequent single pulses in tonic $2^{\circ} \mathrm{VNs}$ were moderately reduced during the stimulus train (Fig. $2 D$, compare insets 1,2$)$. In contrast, in phasic $2^{\circ} \mathrm{VNs}$, the amplitudes of the individual EPSPs decreased considerably during the pulse train compared with the first EPSP (Fig. $2 E$, compare insets 1,2) and reached a minimum at stimulus peak frequency. This difference is compatible with the differential impedance behavior of the two vestibular subtypes during membrane polarization (Beraneck et al., 2007). In particular, the marked reduction of the EPSP amplitude in phasic $2^{\circ} \mathrm{VNs}$ at stimulus peak frequency (Fig. $2 E$, inset 2) complies with the marked impedance decrease of these neurons during depolarization.

In the following, several parameters of the stimulus pulse train, such as peak frequency, cycle length, or single-pulse intensity were varied to reveal the postsynaptic response dynamics in $2^{\circ} \mathrm{VNs}$ during different labyrinthine afferent activity patterns. Although the activity in vestibular nerve afferents, evoked by the different stimulus pulse trains, is an approximation with respect to the synchronicity of the afferent activity pattern during natural head motion in vivo (Ramachandran and Lisberger, 2006; Hospedales et al., 2008), by its defined timing it facilitates the characterization of the neuronal mechanisms underlying a parallel processing of afferent signals in separate populations of central vestibular neurons.

\section{Effect of stimulus train peak frequency}

Compound responses in both tonic and phasic $2^{\circ} \mathrm{VNs}$ evoked by stimulus trains with successively larger peak frequencies $(40,70$, and $100 \mathrm{~Hz}$ ) had similar peak amplitudes but exhibited progressively larger peak advances when the peak frequency was augmented from $40 \mathrm{~Hz}$ to 70 and $100 \mathrm{~Hz}$ (Fig. $3 A_{1}-A_{3}, B_{1}-B_{3}$; Table 1 ). The mean advance of the response peak relative to stimulus peak frequency increased to a similar extent in both types of $2^{\circ} \mathrm{VNs}$ (Fig. 3E; Table 1). However, independent of stimulus peak frequency, the advance was always significantly larger in phasic compared with tonic $2^{\circ} \mathrm{VNs}$ (Fig. $3 E$; Table 1 ). In most phasic $2^{\circ} \mathrm{VNs}$, the compound response had a more pronounced truncation during pulse trains with higher peak frequencies (Fig. $3 B_{2}, B_{3}$, open triangles). This further accentuated the asymmetry of the compound responses and indicates that these neurons have a highly nonlinear synaptic processing of repetitive afferent vestibular inputs. Construction of the population mean responses (Fig. $3 C)$ and smoothed fits $(D)$ from the recordings of phasic $(n=67)$ and tonic $2^{\circ} \mathrm{VNs}(n=14)$, respectively, confirmed the clear differences in postsynaptic signal processing of the two neuronal subpopulations.

Increasing the stimulus peak frequency from $40 \mathrm{~Hz}$ to 70 and $100 \mathrm{~Hz}$ did not only change the time course of the compound responses but also caused an increasingly larger reduction of the individual EPSP size in both tonic and phasic $2^{\circ} \mathrm{VNs}$ (Fig. $3 A_{1}-$ $A_{3}, B_{1}-B_{3}, F$, gray traces; Table 1$)$. This reduction was particularly prominent in phasic $2^{\circ} \mathrm{VNs}$ (Fig. $3 F_{1}, F_{2}$, compare plots) because EPSPs evoked by the single pulses at peak frequency of $100 \mathrm{~Hz}$ were on average $<10 \%$ of the amplitude of the first EPSP (Fig. $3 F_{2}$; Table 1). This suggests the presence of powerful shunting mechanisms for afferent synaptic inputs, preferentially at high stimulus peak frequencies. This shunting likely contributes to the observed truncation of the compound response (Fig. $3 B_{2}, B_{3}$, open triangles) and the increased peak advance at higher peak frequencies. Although some shunting of single EPSPs was also observed in tonic $2^{\circ} \mathrm{VNs}$, the maximal reduction (at $100 \mathrm{~Hz}$ peak frequency) was significantly less than in phasic $2^{\circ} \mathrm{VNs}$ (Fig. $3 F_{1}, F_{2}$; Table 1). Except for stimulus peak frequencies of $40 \mathrm{~Hz}$ the shunting effect on single EPSP size was always more pronounced in phasic compared with tonic $2^{\circ} \mathrm{VNs}$ (Table 1 ).

\section{Effect of stimulus train length}

Using stimulus train length as a variable but keeping peak frequency constant revealed a different dependency of both amplitude and timing of the compound response from this parameter in tonic and phasic $2^{\circ} \mathrm{VNs}$ (Fig. $4 A, B$ ). Compatible with the relatively linear transformation of presynaptic afferent activity into postsynaptic compound responses in tonic $2^{\circ} \mathrm{VNs}$, the response peak almost doubled in amplitude when the stimulus train length (half cycle) was increased from $0.25 \mathrm{~s}$ to $2.5 \mathrm{~s}$ (Fig. $4 A_{1}-A_{4}, C_{1}$, open circles). This finding indicates that the temporal summation of individual EPSPs in tonic $2^{\circ} \mathrm{VNs}$ gradually increases with continuously larger numbers of single pulses in the train and confirms the notion of a mostly linear input-output relationship in this vestibular neuronal subtype. The substantial increase in compound response peak amplitude with increasing train length is accompanied by a considerable change in the timing of the response peak. Notably, the large peak lag of approximately $-45^{\circ}$ at a half-cycle length of $0.25 \mathrm{~s}$ changes into a peak advance of $\sim 20^{\circ}$ at a half-cycle length of $2.5 \mathrm{~s}$ (Fig. $4 C_{2}$, open circles). Accordingly, the compound response peak in tonic $2^{\circ} \mathrm{VNs}$ would be aligned with peak frequency at a half-cycle length of $\sim 1.5 \mathrm{~s}$ (Fig. $4 C_{2}$, dotted arrow to bottom axis).

In phasic $2^{\circ} \mathrm{VNs}$, the amplitude of the compound response evoked during a stimulus half cycle of $2.5 \mathrm{~s}$ increased only by $\sim 25 \%$ compared with the response evoked with a stimulus half cycle of $0.25 \mathrm{~s}$ (Fig. $4 B, C_{1}$ ). This small increment in amplitude during a 10-fold extension in stimulus half-cycle length contrasts with the almost twofold increase in tonic $2^{\circ} \mathrm{VNs}$ (Fig. $4 C_{1}$ ). This is because of the relatively larger responses in phasic $2^{\circ} \mathrm{VNs}(75 \%)$ 

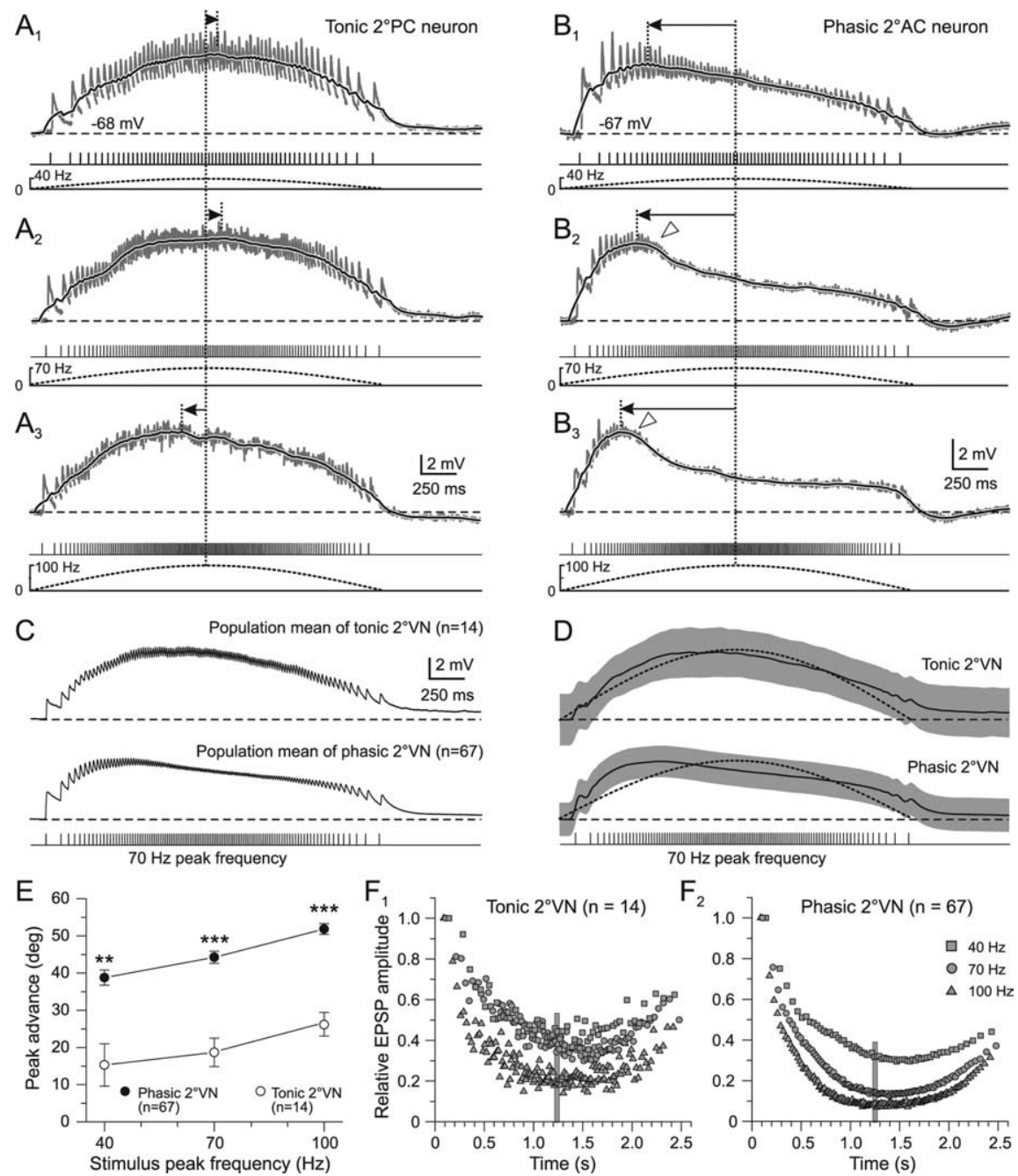

$70 \mathrm{~Hz}$ peak frequency

$\mathrm{F}_{2}$

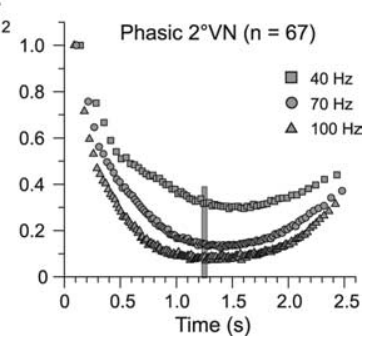

Figure 3. Compound synaptic responses as a function of stimulus train peak frequency in phasic and tonic $2^{\circ} \mathrm{VNs}$. $\boldsymbol{A}_{1}-\boldsymbol{B}_{3}$ Compound responses formed by summation of single EPSPs (gray traces) in a tonic $2^{\circ} \mathrm{PC}\left(\boldsymbol{A}_{\mathbf{1}}-\boldsymbol{A}_{3}\right)$ and a phasic $2^{\circ} \mathrm{AC}\left(\boldsymbol{B}_{1}-\boldsymbol{B}_{3}\right)$ neuron after pulse-train stimulation with a peak frequency of $40\left(\boldsymbol{A}_{1}, \boldsymbol{B}_{1}\right), 70\left(\boldsymbol{A}_{2}, \boldsymbol{B}_{2}\right)$, and $100 \mathrm{~Hz}\left(\boldsymbol{A}_{3}, \boldsymbol{B}_{3}\right)$. The black traces are smoothed fits of the compound responses; bottom traces show pulse trains (half-cycle duration, $2.5 \mathrm{~s}$ ) and stimulus frequency modulation (dashed lines), respectively; horizontal dashed lines indicate the resting membrane potential ( $-68 \mathrm{mV}$ in $A ;-67 \mathrm{mV}$ in $\boldsymbol{B}$ ) and horizontal arrows the lag/advance of the compound response peak with respect to stimulus peak frequency (vertical dotted lines). Synaptic responses in $\boldsymbol{A}_{\mathbf{1}}-\boldsymbol{B}_{\mathbf{3}}$ are the averages of 12 single sweeps. Calibrations in $\boldsymbol{A}_{\mathbf{3}}$ and $\boldsymbol{B}_{\mathbf{3}}$ apply to $\boldsymbol{A}_{\boldsymbol{1}}, \boldsymbol{A}_{\mathbf{2}}$ and $\boldsymbol{B}_{\boldsymbol{1}}$, $\boldsymbol{B}_{2}$, respectively; open arrowheads in $\boldsymbol{B}_{2}$ and $\boldsymbol{B}_{3}$ mark the truncation of the compound response. $\boldsymbol{C}, \boldsymbol{D}$, Population mean of compound responses $(\boldsymbol{C})$ and smoothed fits $(\boldsymbol{D})$ evoked by pulse trains with $70 \mathrm{~Hz}$ peak frequency and $2.5 \mathrm{~s}$ half-cycle length in tonic $(n=14)$ and phasic $2^{\circ} \mathrm{VNs}(n=67)$. The gray bands in $D$ indicate $\pm S E$ of the mean, the dotted curves indicate the stimulus modulation and the horizontal dashed lines the mean resting membrane potential of $-69 \mathrm{mV}$ in tonic and $-68 \mathrm{mV}$ in phasic $2^{\circ} \mathrm{VNs}$. $\boldsymbol{E}$, Advance (in degrees) of the compound response peak relative to stimulus peak frequency (mean $\pm \mathrm{SE}$ ) in phasic $(\mathbf{O})$ and tonic $2^{\circ} \mathrm{VNs}(O)$ as a function of stimulus peak frequency. ${ }^{* *} p \leq 0.001,{ }^{* * *} p \leq 0.0001$, significant difference between tonic and phasic $2^{\circ} \mathrm{VNs}$ (Mann-Whitney $U$ test). $\boldsymbol{F}_{1}, \boldsymbol{F}_{2}$, Average amplitude of individual EPSPs evoked by the single pulses of the train with peak frequencies of $40(\square), 70(\bigcirc)$, and $100 \mathrm{~Hz}(\triangle)$ in tonic $\left(\boldsymbol{F}_{\boldsymbol{1}}\right)$ and phasic $2^{\circ} \mathrm{VNs}\left(\boldsymbol{F}_{2}\right)$. Amplitudes were normalized to the size of the first EPSP. Plots of \pm SE were omitted for clarity; vertical gray bars mark the timing of the stimulus peak frequency.

at a half-cycle length of $0.25 \mathrm{~s}$ compared with tonic $2^{\circ} \mathrm{VNs}(55 \%)$ (Fig. $4 C_{1}$ ). The larger amplitudes in phasic $2^{\circ} \mathrm{VNs}$ during short stimulus trains $(0.25 \mathrm{~s})$ and the rather small increment with increasing train length can be explained by the relatively rapid rise of the compound response generating the considerable peak advance (Figs. 2E, 3B). This small increase in peak amplitudes for half-cycle lengths between 0.25 and $2.5 \mathrm{~s}$, however, is contrasted by a large simultaneous change of peak timing, which exceeded that of tonic $2^{\circ} \mathrm{VNs}$ (Fig. $4 C_{2}$ ). The considerable response peak lag of approximately $-35^{\circ}$ at a half-cycle length of $0.25 \mathrm{~s}$ changed into a peak advance of $\sim 45^{\circ}$ at a half-cycle length of $2.5 \mathrm{~s}$ (Fig.
$4 C_{2}$, filled circles). Calculation of the stimulus half-cycle length at which compound responses in phasic $2^{\circ} \mathrm{VNs}$ were aligned with stimulus peak frequency yielded a value of $\sim 0.7 \mathrm{~s}$ (Fig. $4 C_{2}$, dotted arrow to the bottom axis). This time is considerably shorter than that in tonic $2^{\circ} \mathrm{VNs}(\sim 1.5 \mathrm{~s})$ and again attributable to the faster slope of the compound response during the first few stimuli of the train (Figs. 2E, 3B). Moreover, it complies with the notion that phasic $2^{\circ} \mathrm{VNs}$ are particularly suitable for the detection of short, high-frequency components, whereas tonic $2^{\circ} \mathrm{VNs}$ are better suited to the processing of lowdynamic head motion components.

Effect of single stimulus pulse intensity Higher-intensity single current pulses applied to the vestibular nerve branches recruit increasingly more afferent fibers. This recruitment causes larger amplitudes of all individual monosynaptic EPSPs (Fig. $5 A-F$, inset 1 ) and consequently compound responses with larger peak amplitudes in both tonic (Fig. $5 A-C$ ) and phasic $2^{\circ} \mathrm{VNs}$ (Fig. $5 D-F$ ). With larger intensities of all single pulses of a train $[1.3 \times T$ (Fig. $5 A), 1.8 \times T(B)$, and $3.1 \times T(C)]$, the compound responses evoked by stimulus trains with low-intensity single pulses increased and action potentials were triggered in tonic $2^{\circ} \mathrm{VNs}$ as soon as the spike threshold was reached. The number of evoked spikes during the train stimulation depended on the subthreshold compound response amplitude but consistently was largest around peak stimulus frequency (Fig. $5 B, C$, insets 2). This indicates that in tonic $2^{\circ} \mathrm{VNs}(n=10)$ the evoked discharge is rather linearly related to the underlying synaptic membrane depolarization as for intracellular injected currents (Straka et al., 2004). This effect became more evident when the relative spike discharge rate during the stimulus train (peak frequency, 70 $\mathrm{Hz}$; train half-cycle length, $2.5 \mathrm{~s}$; singlepulse intensity, $>2.5 \times T$ ) was plotted as a function of time (Fig. $5 G_{1}$ ). The maximal spike discharge rate occurs slightly before stimulus train peak frequency (Fig. $5 G_{1}$, arrow) and corresponds with the peak advance of the subthreshold compound response (Fig. 3C). Thus, the spike discharge in these neurons that more or less mirrors the stimulus frequency modulation has a rather tight correlation with the synaptic depolarization.

In phasic $2^{\circ} \mathrm{VNs}$, stimulus-train-evoked compound responses changed from a symmetric waveform at low-intensity single pulses [e.g., $1.4 \times T$ (Fig. 5D)] to a skewed response at highintensity single pulses [2.0×T (Fig. $5 E$ ) and $3.2 \times T(F)]$. Most importantly however, in all phasic $2^{\circ} \mathrm{VNs}(n=31)$, only a small number of action potentials (approximately one to six) were evoked during the first $10-15$ single pulses of the stimulus train 
Table 1. Timing of the compound response peak and reduction of amplitudes of single EPSPs during pulse-train stimulation in phasic and tonic $2^{\circ} \mathrm{VN}$

\begin{tabular}{|c|c|c|c|c|}
\hline \multirow[b]{2}{*}{ Stimulus peak frequency } & \multicolumn{2}{|l|}{ Tonic $2^{\circ} \mathrm{VNs}$} & \multicolumn{2}{|l|}{ Phasic $2^{\circ}$ VNs } \\
\hline & $\begin{array}{l}\text { Peak advance relative to stimulus } \\
\text { peak frequency }\end{array}$ & $\begin{array}{l}\text { Relative size of single EPSPs at } \\
\text { stimulus peak frequency }\end{array}$ & $\begin{array}{l}\text { Peak advance relative to stimulus } \\
\text { peak frequency }\end{array}$ & $\begin{array}{l}\text { Relative size of single EPSPs at } \\
\text { stimulus peak frequency }\end{array}$ \\
\hline $40 \mathrm{~Hz}$ & $15 \pm 5^{\circ}(9)^{*}$ & $46 \pm 10 \%$, n.s. $(9)$ & $38 \pm 2^{\circ}(36)$ & $35 \pm 2 \%(36)$ \\
\hline $70 \mathrm{~Hz}$ & $19 \pm 3^{\circ}(14)^{*}$ & $38 \pm 9 \%(14)^{*}$ & $44 \pm 2^{\circ}(67)$ & $14 \pm 1 \%(67)$ \\
\hline $100 \mathrm{~Hz}$ & $26 \pm 3^{\circ}(9)^{*}$ & $23 \pm 3 \%(9)^{* *}$ & $53 \pm 1^{\circ}(40)$ & $8 \pm 1 \%(40)$ \\
\hline
\end{tabular}

Single EPSP amplitudes at stimulus peak frequencies $(40,70$, and $100 \mathrm{~Hz}$ ) are indicated as a percentage (mean $\pm \mathrm{SE}$ ) of the EPSP evoked by the first pulse in the stimulus train. The timing of the compound response peak is indicated relative to the peak frequency. n.s., Not significant. The number of neurons $(n)$ is shown in parentheses.

${ }^{*} p \leq 0.01 ;{ }^{* *} p \leq 0.001$, significant difference (Mann-Whitney $U$ test) between parameters of phasic and tonic $2^{\circ} \mathrm{VN}$.

(Fig. 5E,F, insets 2). Even with larger single-pulse intensity $(>5 \times T)$ no further increase in spike number or spiking after the first 15 pulses was observed. This is illustrated by plotting the relative spike discharge rate during the stimulus train (Fig. $5 G_{2}$ ). The likelihood for spike triggering is maximal at the third single pulse of the train (Fig. $5 G_{2}$, arrow). This temporal limitation of evoked spikes is compatible with the pronounced peak advance of the subthreshold compound response (Fig. $3 E$ ) and is likely related to the substantial shunting of single EPSPs after the response peak is reached (Fig. $3 F_{2}$ ).

The differential temporal pattern of synaptically evoked spikes in phasic and tonic $2^{\circ} \mathrm{VNs}$ (Fig. $5 G_{3}$ ) was quantified by calculating the stimulus cycle frequency at which the maximal discharge rate (Fig. $5 G_{1}, G_{2}$, arrows) coincides with the stimulus peak. The maximal discharge rate matches the stimulus peak frequency at a cycle frequency of $\sim 1 \mathrm{~Hz}$ in phasic and $\sim 0.25 \mathrm{~Hz}$ in tonic $2^{\circ} \mathrm{VNs}$ (Fig. $5 G_{1}, G_{2}$ ). Accordingly, the differential synaptic spike discharge behavior in phasic and tonic $2^{\circ} \mathrm{VNs}$ (Fig. $5 G_{3}$ ) is compatible with the different intrinsic filter properties and suggests a preferential processing of highand low-dynamics vestibular afferent signals in the two neuronal subtypes, respectively (Beraneck et al., 2007).

\section{Inhibitory neuronal circuits control afferent synaptic signal processing in phasic $2^{\circ} \mathrm{VNs}$}

The early truncation of the compound responses and the marked reduction of single EPSP amplitudes that likely contributes to the peak advance in phasic $2^{\circ} \mathrm{VNs}$ might not only be caused by prominent voltage-dependent potassium conductances (Beraneck et al., 2007), but also by inhibitory synaptic inputs superimposed on the afferent-evoked monosynaptic excitation (Biesdorf et al., 2008). A potential contribution of glycinergic and GABAergic IPSPs to the nonlinear characteristics of compound responses in phasic $2^{\circ} \mathrm{VNs}$ was studied by bath application of the respective transmitter antagonists (Fig. 6A,C). Appli-
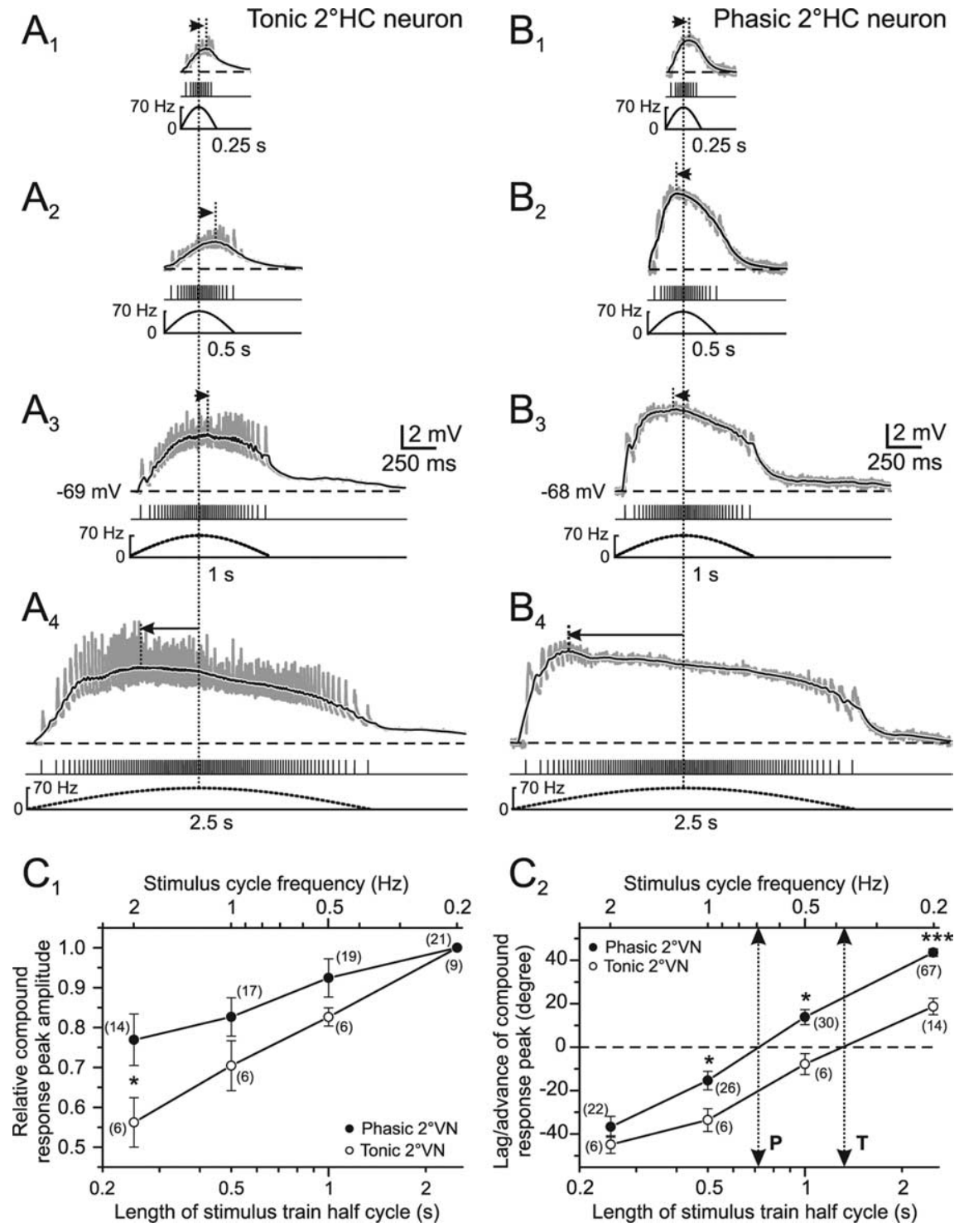

Figure 4. Compound synaptic responses as a function of stimulus pulse train length in phasic and tonic $2^{\circ} \mathrm{VNs}$. $A_{1}-B_{4}$ Compound responses of single EPSPs (gray traces) in a tonic $\left(\boldsymbol{A}_{7}-\boldsymbol{A}_{4}\right)$ and a phasic $\left(\boldsymbol{B}_{1}-\boldsymbol{B}_{4}\right) 2^{\circ} \mathrm{HC}$ neuron after pulse-train stimulation with $0.25\left(\boldsymbol{A}_{1}, \boldsymbol{B}_{1}\right), 0.5\left(\boldsymbol{A}_{2}, \boldsymbol{B}_{2}\right), 1\left(\boldsymbol{A}_{3}, \boldsymbol{B}_{3}\right)$, and $2.5 \mathrm{~s}\left(\boldsymbol{A}_{4}, \boldsymbol{B}_{4}\right)$ half-cycle length. The peak frequency was $70 \mathrm{~Hz}$ and pulse intensity was $1.8 \times T$ in $A$ and $1.7 \times T$ in $B$. Black traces are smoothed fits of the compound responses; bottom traces show pulse trains and stimulus frequency (dashed lines), respectively; horizontal dashed lines indicate the membrane potential ( $-69 \mathrm{mV}$ in $A ;-68 \mathrm{mV}$ in $\boldsymbol{B}$ ) and horizontal arrows indicate the lag/advance in degree of the compound response peak with respect to stimulus peak frequency (vertical dotted lines). All records are the average of 12 responses. Calibrations in $\boldsymbol{A}_{3}$ and $\boldsymbol{B}_{3}$ apply to all other traces. $\boldsymbol{C}_{1}$, $\boldsymbol{C}_{2}$, Mean ( \pm SE) of compound response peak amplitude $\left(\boldsymbol{C}_{7}\right)$ and peak lag/advance relative to stimulus peak frequency $\left(\boldsymbol{C}_{2}\right)$ of tonic $(\bigcirc)$ and phasic $2^{\circ} \mathrm{VNs}(-)$ as a function of stimulus half-cycle length (bottom axis) and corresponding full stimulus cycle frequency (top axis). Amplitudes in $C_{1}$ were normalized to those obtained at a stimulus half-cycle length of $2.5 \mathrm{~s}$; dotted two-sided arrows indicate half-cycle length and corresponding full-cycle frequency where response peak and stimulus peak frequency are aligned $\left(0^{\circ}\right.$; dashed horizontal line) in tonic (T) and phasic (P) $2^{\circ} \mathrm{VNs}$. The number of neurons is indicated in parentheses. ${ }^{*} p \leq$ $0.05,{ }^{* * *} p \leq 0.0001$, significance of difference between tonic and phasic neurons (Mann-Whitney $U$ test). 
A
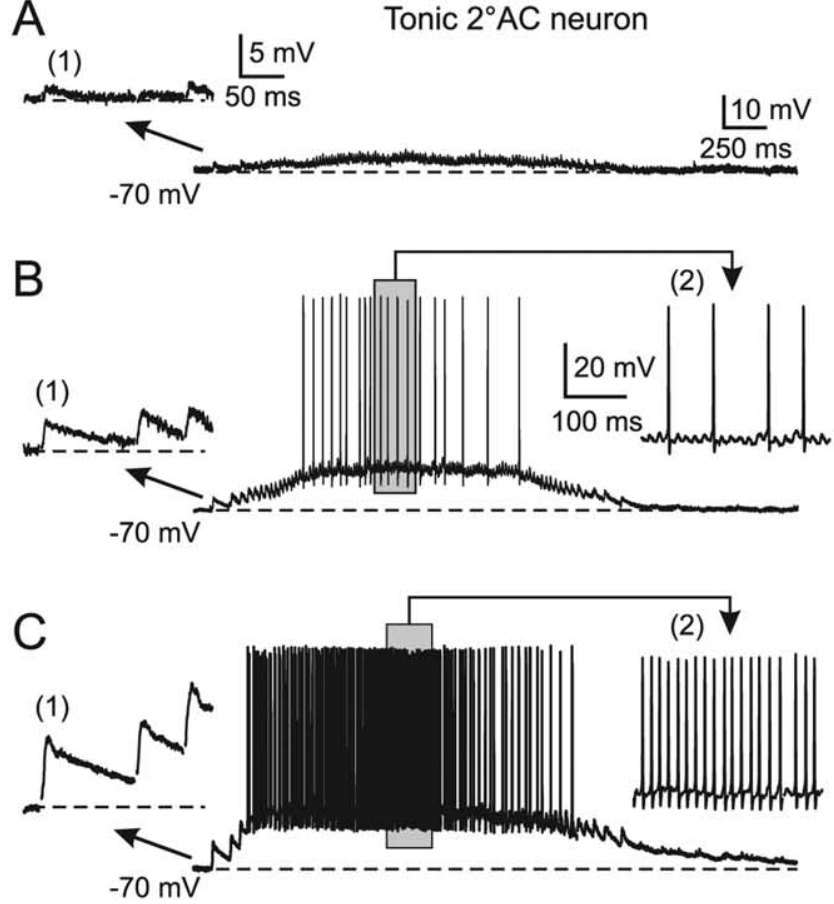

Stimulus

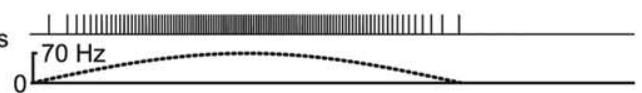

D
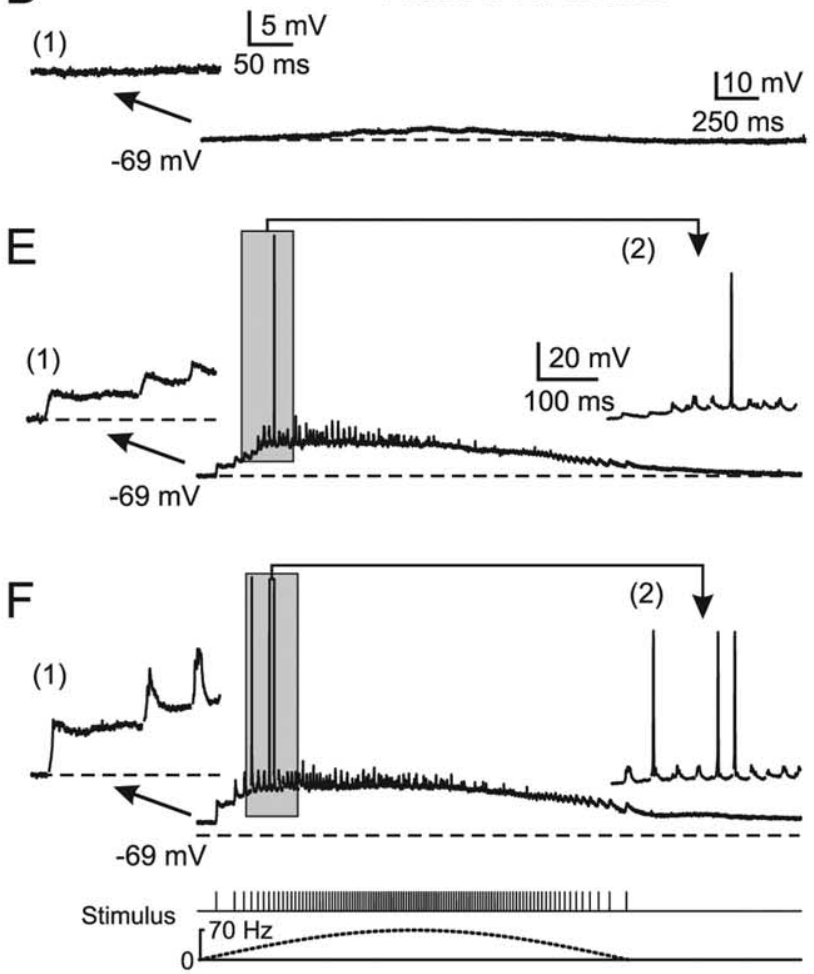

G

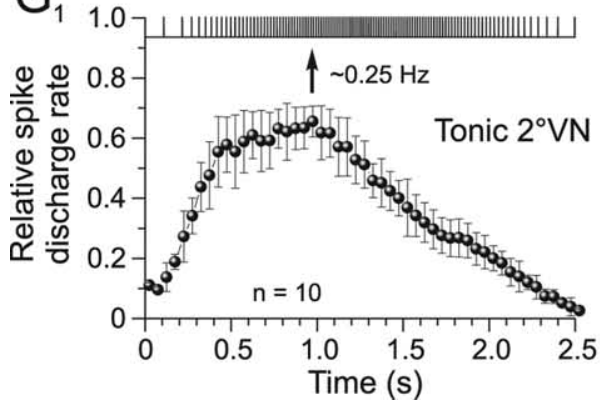

$\mathrm{G}_{2}$

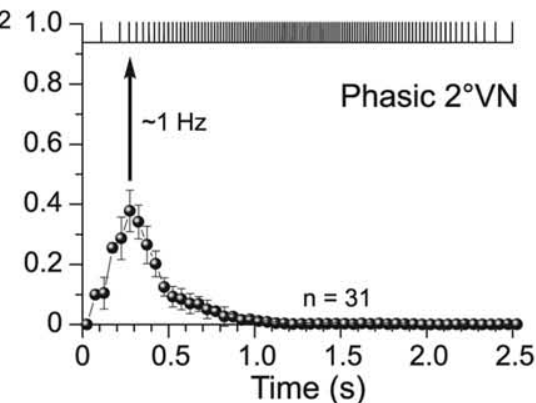

$\mathrm{G}_{3}$

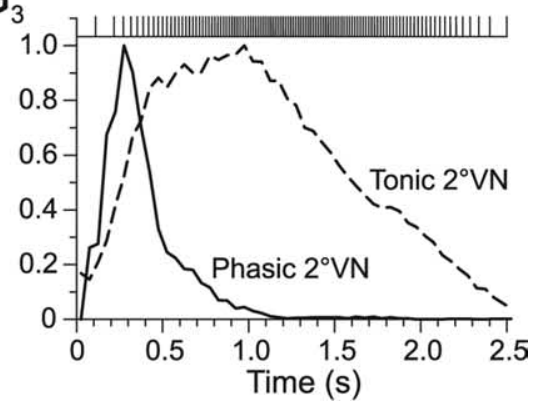

Figure 5. Synaptic discharge dynamics as a function of stimulus pulse intensity in phasic and tonic $2^{\circ} \mathrm{VNs}$. $\boldsymbol{A}-\boldsymbol{F}$, Compound responses and superimposed spikes in a tonic $(\boldsymbol{A}-\boldsymbol{C})$ and a phasic $(\boldsymbol{D}-\boldsymbol{F})$ $2^{\circ} \mathrm{AC}$ neuron after stimulation with sinusoidal pulse trains at a peak frequency of $70 \mathrm{~Hz}$. The intensities for the single pulses were in the tonic $2^{\circ} \mathrm{AC}(\boldsymbol{A}, 1.3 \times T ; \boldsymbol{B}, 1.8 \times T ; \boldsymbol{C}, 3.1 \times T)$ and in the phasic $2^{\circ} A C$ neuron $(\boldsymbol{D}, 1.4 \times T ; \boldsymbol{E}, 2.0 \times T ; \boldsymbol{F}, 3.2 \times T)$; the first three single EPSPs of the train (1) and during the indicated period (gray area) of spike discharge (2) in $\boldsymbol{A}-\boldsymbol{F}$ are shown at an extended time and amplitude scale; bottom traces in $\boldsymbol{C}$ and $\boldsymbol{F}$ show pulse trains (half-cycle duration, $2.5 \mathrm{~s}$ ) and stimulus frequency (dashed lines) that also apply to $\boldsymbol{A}, \boldsymbol{B}$ and $\boldsymbol{D}, \boldsymbol{E}$, respectively. Horizontal dashed lines indicate the membrane potential ( $-70 \mathrm{mV}$ in $\boldsymbol{A}-\boldsymbol{C} ;-69 \mathrm{mV}$ in $\boldsymbol{D}-\boldsymbol{F}$ ); records in $\boldsymbol{B}, \boldsymbol{C}$ and $\boldsymbol{E}, \boldsymbol{F}$ are single sweeps and in $\boldsymbol{A}$ and $\boldsymbol{D}$, the average of 12 responses, respectively. Calibrations in $\boldsymbol{A}$ and $\boldsymbol{D}$ and insets (1) therein apply also to $\boldsymbol{B}, \boldsymbol{C}$ and $\boldsymbol{E}, \boldsymbol{F}$, respectively; calibration in insets (2) in $\boldsymbol{B}$ and $\boldsymbol{E}$ apply also to insets (2) in $\boldsymbol{C}$ and $\boldsymbol{F}$, respectively. $\boldsymbol{G} \mathbf{7}-\boldsymbol{G}$, Relative rate of evoked spike discharge (mean \pm SE) during pulse trains with peak frequencies of $70 \mathrm{~Hz}$ in tonic $\left(\boldsymbol{G}_{\mathbf{1}}\right)$ and phasic $2^{\circ} \mathrm{VNs}\left(\boldsymbol{G}_{2}\right)$ at single-pulse intensity $>2.5 \times T$. The relative rate was calculated from the number of spikes in each cell during the stimulus train in $50 \mathrm{~ms}$ bins and divided by the number of stimuli within the respective bin. The discharge in phasic $2^{\circ} \mathrm{VNs}$ is confined to the first $10-15$ single pulses of the train $\left(\boldsymbol{G}_{\mathbf{3}}\right.$, solid line), whereas in tonic $2^{\circ}$ VNs it is more aligned with the frequency modulation of the single pulses ( $\boldsymbol{G}_{\mathbf{3}}$, dashed line). Curves in $\boldsymbol{G}_{\mathbf{3}}$ were obtained by normalization to the peaks in $\boldsymbol{G}_{\mathbf{1}}$ and $\boldsymbol{G}_{\mathbf{2}}$, respectively. Peak discharge rate in tonic and phasic $2^{\circ} \mathrm{VNs}\left(\boldsymbol{G}_{\mathbf{1}}, \boldsymbol{G}_{\mathbf{2}}\right.$, arrows) corresponds to a full stimulus cycle of $\sim 0.25$ and $\sim 1 \mathrm{~Hz}$, respectively.

cation of the glycine receptor antagonist strychnine $(1 \mu \mathrm{M} ; n=7)$ or the $\mathrm{GABA}_{\mathrm{A}}$ receptor antagonist bicuculline $(1-5 \mu \mathrm{M} ; n=8)$ caused a significant reversible increase of the compound response amplitude by $\sim 2 \mathrm{mV}$ and a decrease of the mean peak advance by $>20^{\circ}$ compared with controls (Fig. $6 A, C, H, I$ ). Moreover, the observed reduction of single EPSP amplitudes during the stimulus train in controls became smaller after application of both transmitter antagonists (Fig. 6B,D). Although, this effect was significant only after blocking the GABAergic transmission (Fig. $6 D$, asterisk), it suggests that at least part of the observed shunting during the stimulus train was caused by inhibitory inputs. Probable neuronal candidates for mediating the glycinergic and GABAergic inhibition are ipsilateral vestibular inhibitory inter- neurons (Straka and Dieringer, 1996) that have been shown to activate disynaptic IPSPs in phasic, but not in tonic $2^{\circ} \mathrm{VNs}$ after electrical stimulation of vestibular nerve afferent fibers (Biesdorf et al., 2008). An ipsilateral origin was confirmed by the recordings of several phasic $2^{\circ} \mathrm{VNs}(n=6)$ in isolated frog brains in which the midline was completely transected from the optic tectum to the obex. The peak advance of the compound responses of these neurons was identical to those of controls, thereby excluding commissural connections as the source of the inhibition.

The larger effect of bicuculline with respect to strychnine on the shunting of single EPSP amplitude during the pulse-train stimulus suggests that GABAergic inputs might be either more effective or more numerous. However, GABAergic IPSPs from 
inhibitory vestibular interneurons have shorter time constants than glycinergic IPSPs (Biesdorf et al., 2008), suggesting that additional GABAergic circuits might be recruited by the pulse-train stimulation in the present study. Because all experiments were performed in the isolated frog brain in which the cerebellum was attached (Fig. $6 G)$, it is possible that the activation of vestibular nerve afferent fibers recruits the cerebellar circuitry and thereby evokes Purkinje-cell-mediated GABAergic IPSPs (Magherini et al., 1975) in phasic $2^{\circ} \mathrm{VNs}$. Pressure injection of $100-150 \mathrm{nl}$ of $2 \% \mathrm{li}$ docaine $(n=16)$ into the ipsilateral cerebellar peduncle (Fig. 6G) that blocks the activation of the cerebellar circuitry provoked, in some of the phasic $2^{\circ} \mathrm{VNs}(n=7$ of 16), a reversible increase of the compound response amplitude by $\sim 1 \mathrm{mV}$ as well as a reduction of the peak advance by $\sim 25^{\circ}$ compared with controls (Fig. $6 E, H, I)$, but had no effect in others $(n=9$ of 16). The accompanying reduction of the shunt of single EPSP amplitudes during the stimulus pulse train, however, was not significant (Fig. 6F). A spread of pressureinjected lidocaine from the cerebellum into the vestibular nuclei as a potential explanation of the effect was ruled out because the amplitude of the monosynaptic EPSPs in the $2^{\circ} \mathrm{VNs}(n=16)$, as well as of presynaptic and postsynaptic vestibular afferent field potential components (verified in control experiments) after single electrical pulse stimulation did not decrease. This amplitude constancy served as an indication that no block of action potentials in vestibular afferent fibers occurred within the vestibular nuclei. The effects on the compound response after injection of lidocaine into the cerebellum were confirmed in experiments where phasic $2^{\circ} \mathrm{VNs}(n=18)$ were recorded in isolated whole brains $(n=4)$ in which the cerebellum was removed. In fact, the peak advance of compound responses in phasic $2^{\circ} \mathrm{VNs}$ recorded in these preparations was significantly reduced by $\sim 20^{\circ}$ in 12 of the 18 neurons compared with controls (Fig. 6I).

\section{Modeling approach to reveal cellular and network contributions for signal processing in $2^{\circ} \mathrm{VNs}$}

To differentiate between contributions of intrinsic membrane properties and the properties of network circuitry in shaping postsynaptic signals in $2^{\circ} \mathrm{VNs}$, a modeling approach was used. Minimal models consisting of a soma and a three compartmental dendrite with uniformly distributed conductances were generated from frequency domain data of tonic and phasic $2^{\circ} \mathrm{VNs}$ (Fig. 7 ) (for details, see the supplemental ma-
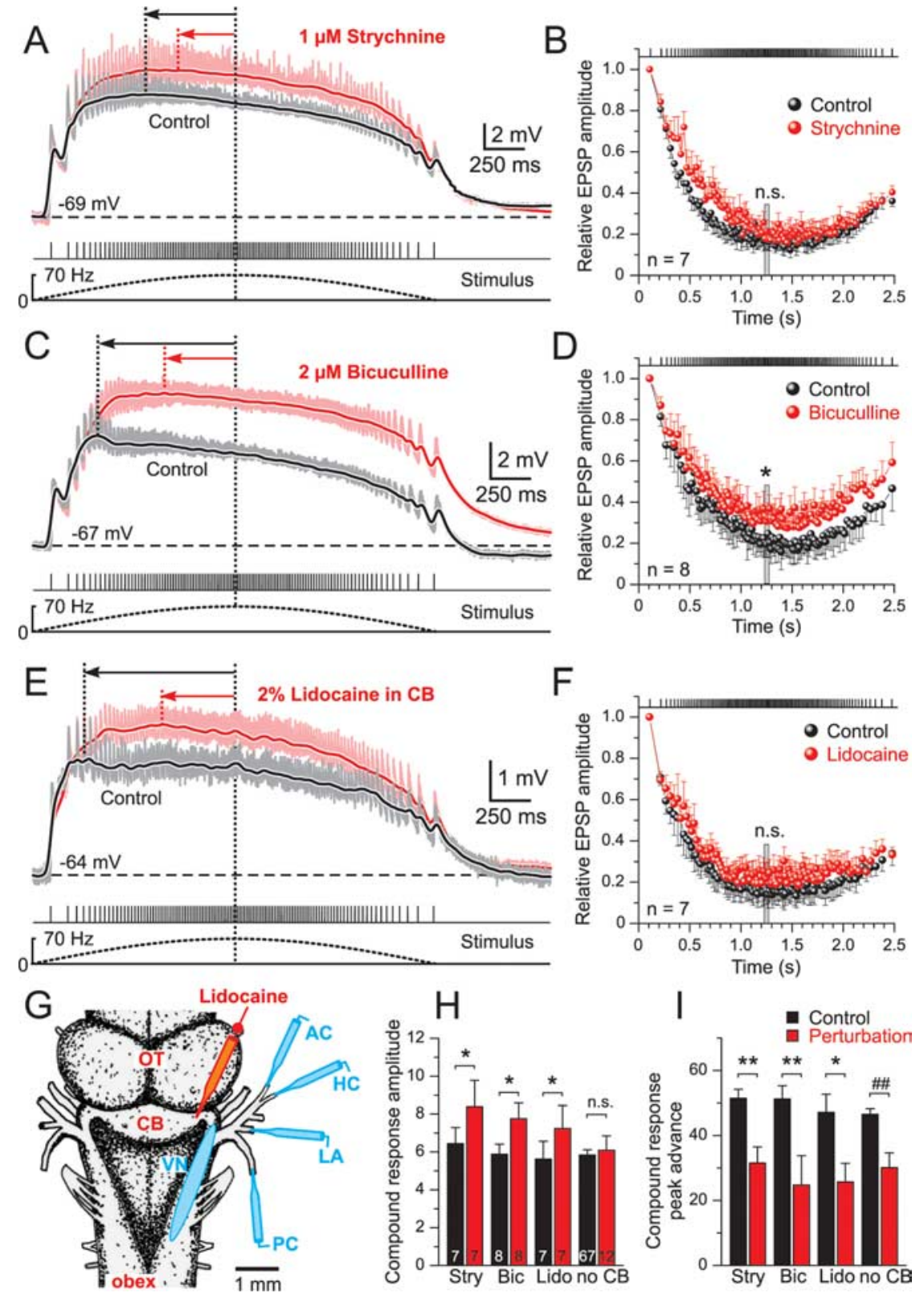

Figure 6. Inhibitory control of compound synaptic responses in phasic $2^{\circ} \mathrm{VNs} . \boldsymbol{A}, \boldsymbol{C}, \boldsymbol{E}$, Effect of blocking the glycinergic (strychnine, $\boldsymbol{A}$ ) and GABAergic transmission (bicuculline, $\boldsymbol{C}$ ) and the cerebellar output (100-150 $\mathrm{nl}$ of lidocaine in $(B, E)$ on amplitude and timing of the compound responses in three different phasic $2^{\circ} \mathrm{VNs}$. Responses were evoked by stimulation of the anterior vertical $(\boldsymbol{A}, \boldsymbol{E})$ or horizontal semicircular canal nerves $(\boldsymbol{C})$ with sinusoidal pulse trains of $70 \mathrm{~Hz}$ peak frequency. The black and red traces are smoothed fits of the compound responses (gray and pink traces); bottom traces show pulse trains (half-cycle duration, $2.5 \mathrm{~s}$ ) and stimulus frequency (dashed lines), respectively; horizontal dashed lines indicate membrane potentials ( $-69 \mathrm{mV}$ in $A ;-67 \mathrm{mV}$ in $\boldsymbol{C} ;-64 \mathrm{mV}$ in $\boldsymbol{E}$ ), and black and red horizontal arrows the peak advance relative to stimulus peak frequency (vertical dotted lines). All records are the average of 12 responses. $\boldsymbol{B}, \boldsymbol{D}, \boldsymbol{F}$, Amplitudes (mean $\pm \mathrm{SE}$ ) of individual EPSPs evoked by single pulses of the train before (black) and after (red) drug application; amplitudes were normalized to the first EPSP, respectively. Vertical gray bars mark the timing of stimulus peak frequency. $\mathbf{G}$, Schematic drawing illustrating the stimulation of individual vestibular nerve branches, the vestibular nuclei, and the site for injection of lidocaine into the ipsilateral cerebellar peduncle. $\boldsymbol{H}, \boldsymbol{I}$, Amplitude $(\boldsymbol{H})$ and timing $(\boldsymbol{I})$ of the compound response peak (mean $\pm \mathrm{SE}$ ) before and after application of strychnine (Stry), bicuculline (Bic), pressure injection of lidocaine (Lido) into the ipsilateral cerebellar peduncle, or after surgical removal of the cerebellum (no CB). ${ }^{*} p \leq 0.05,{ }^{* *} p \leq 0.01$, significance of difference before and after drug application (Wilcoxon signed-rank test); ${ }^{\# \#} p \leq 0.01$ (Mann-Whitney $U$ test), significance between controls and $2^{\circ} \mathrm{VNs}$ recorded after the removal of the cerebellum. n.S., Not significant; $C B$, cerebellum; $0 T$, optic tectum.

terial, available at www.jneurosci.org). Compatible with previous results (Beraneck et al., 2007), a noninactivating sodium conductance was required to obtain the observed increase in impedance with depolarization in tonic $2^{\circ} \mathrm{VNs}$ (Fig. $7 A$ ). In contrast, for 
A
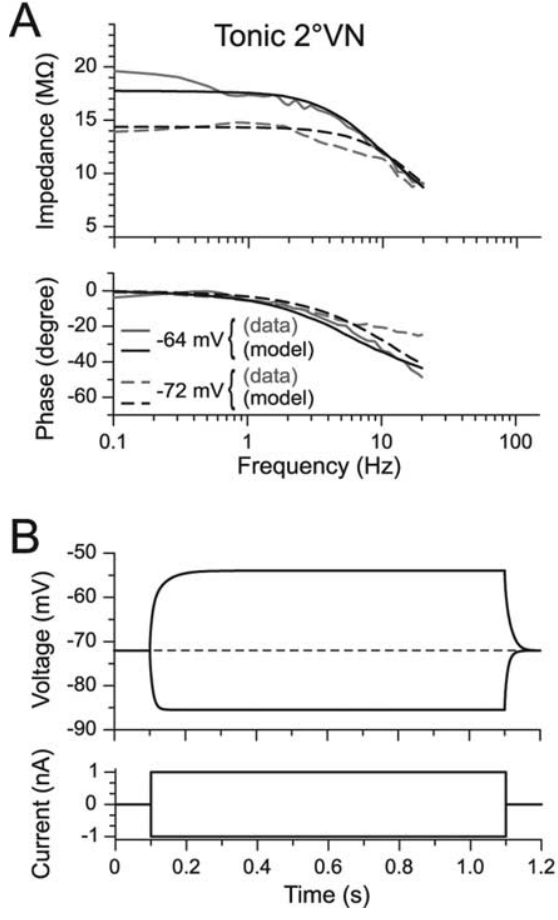

Figure 7. Frequency responses of tonic and phasic compartmental models of $2^{\circ} \mathrm{VNs}$ superimposed on magnitude and phase data used for parameter estimation. $\boldsymbol{A}, \boldsymbol{C}$, Impedance and phase functions of tonic $(\boldsymbol{A})$ and phasic $2^{\circ} \mathrm{VNs}(\boldsymbol{C})$ at two different membrane potentials, computed from published data (Beraneck et al., 2007). Gray curves indicate data and black curves are tonic and phasic neuronal model fits using parameter estimation methods described previously (Saint Mleux and Moore, 2000). For cell parameter values, see the supplemental material (available at www.jneurosci.org as supplemental material). $\boldsymbol{B}, \boldsymbol{D}$, Reconstruction of real-time current step responses of the tonic $(\boldsymbol{B})$ and the phasic model neuron $(\boldsymbol{D})$ using the compartmental models with respective parameters; the asymmetry between depolarizing and hyperpolarizing responses of the phasic neuron model $(\boldsymbol{D})$ as well as the characteristic initial transient in response to positive current steps ( $\boldsymbol{D}$, asterisk) matches the real data (Straka et al., 2004).

phasic $2^{\circ} \mathrm{VNs}$, an inactivating potassium conductance (Bekkers and Delaney, 2001) as well as a delayed rectifier was required to quantitatively describe the particular potential dependence of the resonance behavior (Fig. 7C). Using parameters derived from the impedance data, simulations with the three compartment cable model (Fig. $7 B, D$ ) adequately predicted membrane potential responses to current steps, including a depolarization-induced damped oscillation in phasic $2^{\circ} \mathrm{VNs}$ (Fig. $7 D$, asterisk). The similar responses of model and frog phasic $2^{\circ} \mathrm{VNs}$ supports the particular role of the potassium conductances in generating the distinct resonance and the dynamic response pattern of this neuronal vestibular subtype (Straka et al., 2004; Beraneck et al., 2007).

The role of intrinsic cellular properties in causing the observed dynamics of synaptic compound responses was tested by extending the "single-neuron models" of tonic and phasic $2^{\circ} \mathrm{VNs}$ by excitatory conductance-based synapses ( $E$ compartmental model) (for parameters, see Material and Methods). This allowed mimicking the repetitive synaptic excitation of $2^{\circ} \mathrm{VNs}$ by vestibular nerve afferent fibers as performed in the present study. Calculation of the synaptic compound response characteristics as a function of different stimulus parameters shows that these extended single-neuron models yield results (Fig. $8 A_{1}, A_{2}$, filled circles, open circles) that were at least qualitatively similar to the obtained data, illustrating the functional consequences of the different dynamic properties of phasic and tonic $2^{\circ} \mathrm{VNs}$. Therefore, the characteristic intrinsic cellular properties contribute to some extent to the observed differences in compound response peak timing of the two vestibular neuronal subtypes (Fig. $8 A_{1}, A_{2}$, filled circles, open circles). However, the assumed cellular properties in the model were not sufficient to account for the precise response characteristics as e.g., the large peak advance seen in phasic $2^{\circ} \mathrm{VNs}$ (Figs. $3 C, 4 C_{2}$ ).

Based on the experimental results concerning inhibitory inputs from ipsilateral vestibular networks in phasic but not tonic $2^{\circ} \mathrm{VNs}$ after electrical nerve stimulation (Biesdorf et al., 2008), a combination of excitatory and superimposed inhibitory synapses was added to the single-neuron model (E/I compartmental model). All parameters related to amplitude and time course of monosynaptic afferent excitation and disynaptic GABAergic and glycinergic inhibition (for details, see Material and Methods and supplemental material, available at www.jneurosci.org) have been adapted to values obtained from empiric experiments (Biesdorf et al., 2008). This procedure allowed the generation of model fits of single-pulse-activated afferent monosynaptic EPSPs and superimposed disynaptic GABAergic and glycinergic IPSPs (Fig. 8B). The estimated EPSP and IPSP parameters were used to reconstruct compound responses after pulse-train stimulation at a stimulus peak frequency of $70 \mathrm{~Hz}$ and half-cycle length of $2.5 \mathrm{~s}$ (Fig. $8 C_{1}$ ). The assumption of conductance-based inhibitory synapses yielded model response values similar to those of real frog phasic $2^{\circ} \mathrm{VNs}$ (compare Fig. $8 A_{1}, A_{2}$, filled squares, with $3 E, 4 C_{2}$ ). After turning off the glycinergic and GABAergic inhibition, the reconstructed model compound responses show that these components are particularly important for the timing of the response in phasic $2^{\circ} \mathrm{VNs}$ and considerably enhance the peak advance caused by the intrinsic cellular properties (Fig. $8 C_{1}$ ). This indicates that the particular response dynamics of this neuronal subtype originate from both the intrinsic membrane properties as well as the emerging properties of the inhibitory synaptic circuitry in which these neurons are embedded.

Previous studies have shown that the disynaptic GABAergic and glycinergic IPSPs in phasic $2^{\circ} \mathrm{VNs}$ are mediated by inhibitory neurons in the ipsilateral vestibular nucleus (Straka and Dieringer 1996, 2000; Biesdorf et al., 2008). To obtain realistic reconstructions of control model responses of phasic $2^{\circ} \mathrm{VNs}$ after pulse-train stimulation (compare Fig. $8 C_{1}$, control, with $3 C$ ), it was necessary to assume that both GABAergic and glycinergic inhibitory neurons fire spikes during pulse-train stimulation with a pattern typical for tonic $2^{\circ} \mathrm{VNs}$ (Fig. $8 D_{1}$ ). Using the alternative assumption, i.e., that the disynaptic inhibition is exclusively mediated by neurons with discharge patterns typical for phasic $2^{\circ} \mathrm{VNs}$ (Fig. $8 \mathrm{D}_{2}$ ), the resulting model compound response exhibited a dynamics (Fig. $8 C_{2}$, black trace) that is incompatible with the experimental data (compare Fig. $8 C_{1}$, control). The delayed rapid increase in the response amplitude (Fig. $8 C_{2}$, arrowhead) was caused by the restricted effect of the inhibition in the model response attributable to the temporally limited discharge of the hypothetical phasic inhibitory neurons (Fig. $8 D_{2}$ ). 
The testable prediction from this modeling approach in future studies thus is that tonic ipsilateral vestibular neurons mediate the observed disynaptic inhibition onto phasic $2^{\circ} \mathrm{VNs}$.

\section{Discussion}

Frequency-modulated electrical pulsetrain stimulation of individual vestibular nerve branches activated synaptic responses in frog tonic and phasic $2^{\circ} \mathrm{VNs}$ with distinctly different profiles. The mostly linear transformation of the presynaptic afferent activity into postsynaptic responses in tonic $2^{\circ} \mathrm{VNs}$ complies with the linear intrinsic properties and low-pass filter characteristics of these neurons and suggests an implication in the processing of low-dynamic, tonic components of head motion. In contrast, responses of phasic $2^{\circ} \mathrm{VNs}$ exhibited highly asymmetric profiles because of distinct bandpass filter properties and the impact of inhibitory inputs from vestibular and cerebellar circuits. Accordingly, phasic $2^{\circ} \mathrm{VNs}$ form adequate central vestibular elements optimized for processing of high-dynamic, nonlinear head motion components.

\section{Limitations of the stimulus paradigm}

Vestibular afferent fibers cover a broad spectrum of response dynamics during head rotation (Goldberg, 2000). The heterogeneity in afferent spiking during natural activation causes an asynchronous postsynaptic input in $2^{\circ} \mathrm{VNs}$ that is important for the high-fidelity linear response behavior of the vestibulo-ocular reflex (VOR) (Ramachandran and Lisberger, 2006; Hospedales et al., 2008). The sinusoidally modulated electrical pulse trains in the present study cause mainly synchronized vestibular afferent activity. Thus, imitation of head motion-related afferent discharge in vitro is an approximation with respect to presynaptic discharge timing and recruited fiber spectrum. However, it facilitates investigating the transformation of well-defined presynaptic vestibular afferent activity into postsynaptic responses of tonic and phasic $2^{\circ} \mathrm{VNs}$. Thus, the use of in vivo discharge patterns as a template for electrical stimulation in vitro is well suited to understand the cellular basis for a differential processing of vestibular sensory signals in $2^{\circ} \mathrm{VNs}$.

\section{Coadaptation of intrinsic membrane and emerging network properties of $2^{\circ} \mathrm{VNs}$}

The different, oppositely oriented response properties of frog tonic and phasic $2^{\circ} \mathrm{VNs}$ (Beraneck et al., 2007) and the differential insertion into inhibitory synaptic circuits (Biesdorf et al., 2008) suggest that intrinsic membrane and emerging network properties are functionally coadapted. Together with the different dynamics of pulse train-evoked compound responses, this supports the idea that each of the two subtypes is optimally adapted for a particular role in vestibular sensory-motor transformation. Accordingly, tonic $2^{\circ} \mathrm{VNs}$ as low-pass filters are well
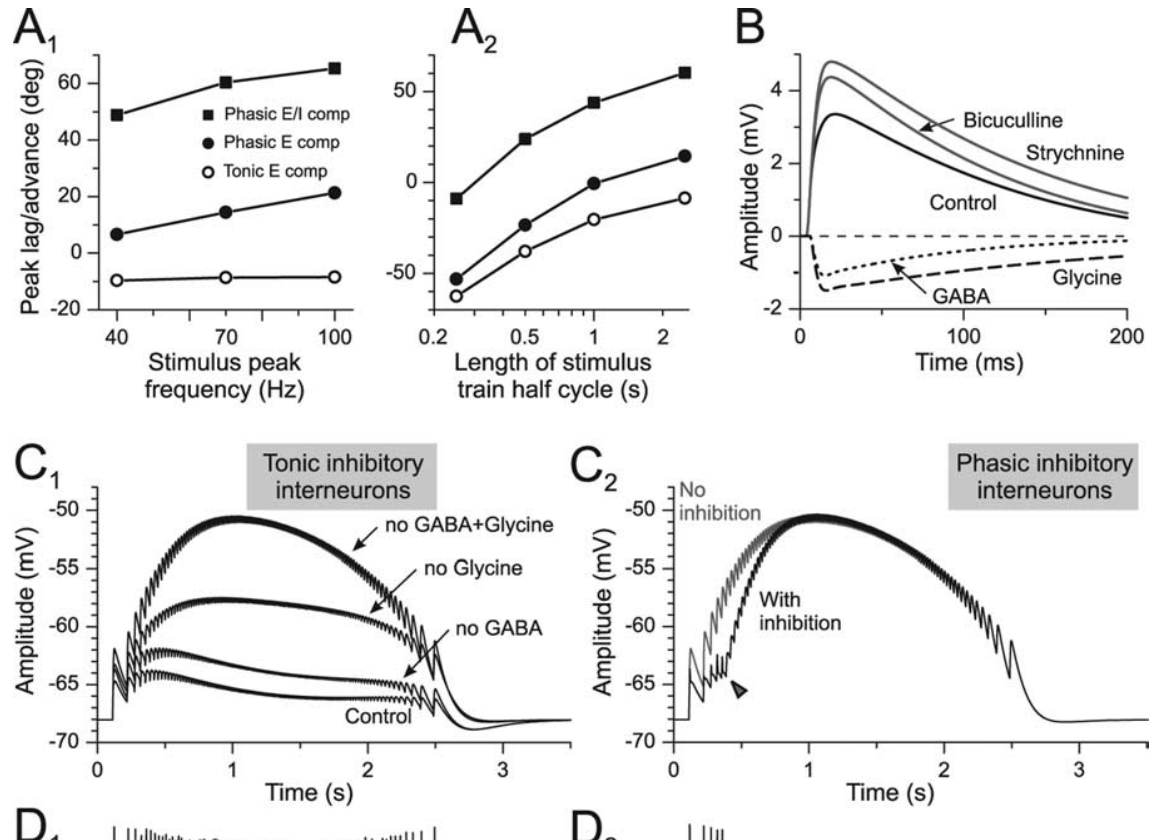

Figure 8. Compound responses generated from intrinsic compartmental models extended by excitatory ( $E$ compartmental stimulus peak frequency $\left(\boldsymbol{A}_{\mathbf{1}}\right)$ or half-cycle length $\left(\boldsymbol{A}_{2}\right)$ of model compound responses reconstructed from tonic $(\bigcirc)$ and phasic $(\mathbf{O}$ compartmental models; appropriate conductances that mimic the disynaptic inhibition (E/I compartmental model) cause the nerve-evoked monosynaptic EPSPs before (control) and after application of bicuculline or strychnine in phasic $2^{\circ} \mathrm{VNs}$; subtraction 列 年 (he mown in $\boldsymbol{C}_{1} ;$ the arrowhead in $\boldsymbol{C}_{\mathbf{2}}$ indicates the increase of the momplitude tributable to the termination of the limited discharge $\left(\boldsymbol{D}_{2}\right)$ if the inhibitory interneurons were phasic type $2^{\circ} \mathrm{VNs}$; recordings in $\boldsymbol{D}_{\mathbf{1}}$ and $\boldsymbol{D}_{2}$ are single sweeps; dashed lines indicate the resting membrane potential $\left(-66 \mathrm{mV}\right.$ in $\boldsymbol{D}_{\boldsymbol{1}} ;-62 \mathrm{mV}$ in $\left.\boldsymbol{D}_{\mathbf{2}}\right)$. The calibration in $\boldsymbol{D}_{2}$ applies to $\boldsymbol{D}_{1}$; bottom traces in $\boldsymbol{D}_{\mathbf{1}}$ and $\boldsymbol{D}_{2}$ show pulse trains and stimulus frequency (dotted lines).

suited for the processing of low-frequency head motion components with a relatively linear transformation of presynaptic afferent activity patterns into postsynaptic responses. In contrast, phasic $2^{\circ} \mathrm{VNs}$ are most suitable for processing transient, highfrequency components with an input-output function that is rather nonlinear as evidenced by the timing of peak discharge rate (Fig. $5 G_{2}$ ). The large nonlinearity of the latter neuronal subtype is caused by a fast and efficient EPSP summation and a subsequent shunting of the input, particularly during high-frequency presynaptic afferent activity (Fig. $3 B$ ). The shunting is mostly attributable to the combined effect of voltage-dependent potassium conductances (Beraneck et al., 2007) and a potent disynaptic inhibition after the monosynaptic EPSP (Biesdorf et al., 2008). Although the experimental data do not allow a distinction between relative contributions of intrinsic and network properties in shaping the synaptic responses, our modeling approach suggests that the feedforward inhibition contributes considerably to the generation of the highly asymmetric response profile in phasic $2^{\circ} \mathrm{VNs}$, thus facilitating the effects of the intrinsic cellular characteristics.

The distinct differences of pulse-train evoked synaptic re- 
sponses in frog tonic and phasic $2^{\circ} \mathrm{VNs}$ is suitable to form the cellular basis for a processing of VOR signals in parallel, frequency-tuned channels that mediate linear (tonic) and nonlinear (phasic) components, respectively (Minor et al., 1999). Separate information channels occur at the sensory periphery (Goldberg, 2000) as well as at the extraocular motor level as evidenced by the presence of functional elements with different morphophysiological properties (Büttner-Ennever, 2005; Spencer and Porter, 2005). In frog, this is evidenced by the presence of abducens motoneurons with different response profiles (Dieringer and Precht, 1986). The large advance and nonlinear pattern of the discharge in phasic $2^{\circ} \mathrm{VNs}$ during sinusoidal pulsetrain stimulation of semicircular canal nerves (Fig. 5 E, F, $\mathrm{G}_{2}$ ) concurs with the particular contribution of eye movements to gaze stabilization in frogs (Dieringer, 1987). During sinusoidal head rotation, compensatory eye motion consists of a rapid, transient eye velocity peak followed by a rather stable eye position. Although the eye velocity shows a transient profile during sinusoidal table rotation, combined eye/head movements generate perfect compensatory gaze movements. The observed different dynamic eye motion components are coherent with an activation of extraocular motoneurons by a combination of signals from phasic and tonic $2^{\circ} \mathrm{VNs}$ (Fig. $5 G_{1}-G_{3}$ ) stimulated with the same cycle length of table rotation as in vivo (Blanks and Precht, 1976; Dieringer, 1987). Given that both tonic and phasic $2^{\circ} \mathrm{VNs}$ project directly to extraocular targets (Straka et al., 2004), the discharge patterns of the two vestibular cell types are well suited to generate the necessary premotor commands for the different dynamic eye motion components during gaze stabilization in frog.

\section{Common principles of vertebrate central vestibular information processing}

The independent adaptive control of different dynamic aspects of angular VOR suggests that the mediation of linear and nonlinear components in separate sensory-motor channels (Lisberger et al., 1983; Minor et al., 1999; Lasker et al., 2000; Clendaniel et al., 2002; Ramachandran and Lisberger, 2006) is a general feature of vertebrate vestibular information processing. Such a parallel processing requires that different dynamic aspects of head motionrelated vestibular signals are not only coded in separate vestibular sensory (Goldberg, 2000) and extraocular motor channels (Büttner-Ennever, 2005; Spencer and Porter, 2005) but are also processed centrally within separate populations of $2^{\circ} \mathrm{VNs}$. In frog, tonic and phasic $2^{\circ} \mathrm{VNs}$ are ideally suited for a separate central processing of linear and nonlinear components. Appropriate homologues for a respective parallel processing in mammals might be tonic and "kinetic" vestibular neurons described in cat (Shimazu and Precht, 1965) or rodent type A and B medial vestibular nucleus (MVN) neurons (Babalian et al., 1997). The latter types exhibit adequate cellular properties necessary for differential signal processing (Straka et al., 2005) mostly based on differences in potassium conductances (Gittis and du Lac, 2007).

In frog, the differential tuning of synaptic response dynamics in $2^{\circ} \mathrm{VNs}$ depends on intrinsic membrane properties as well as on inhibitory side loops. The connectivity of these circuits is likely not a particularity of frogs but rather a common vertebrate feature. The similarities of vestibular network organization in different vertebrates (Straka and Dieringer, 2004) suggest that the sensory-motor transformation of head motion-related signals in mammals is also controlled by similarly organized side loops (Minor and Goldberg, 1991). Thus, a differential insertion of, for example, rodent type A and B MVN neurons into inhibitory and excitatory circuits is likely and might allow an independent ad- aptation and modification of particular dynamic aspects. Given a fundamental functional equivalence of central vestibular neurons in different vertebrates (Straka et al., 2005), intrinsic membrane and emerging network properties of mammalian vestibular subgroups might be coadapted as in frogs.

\section{Inhibitory control of vestibular responses}

An ipsilateral disynaptic GABAergic and glycinergic inhibition that facilitates nonlinear response components in frog phasic $2^{\circ} \mathrm{VNs}$ (Biesdorf et al., 2008) is likely also present in a subgroup of mammalian central vestibular neurons. Mouse type B MVN neurons, functional homologues of frog phasic $2^{\circ} \mathrm{VNs}$, receive considerably more spontaneous glycinergic and GABAergic inputs from ipsilateral vestibular interneurons than type A MVN neurons (Camp et al., 2006). A feedforward side loop that mediates an inhibition on type B MVN neurons could originate from a subset of type-A-like GABAergic neurons in the parvocellular part of the MVN (Bagnall et al., 2007; Gittis and du Lac, 2007, 2008). This putative organization in mouse matches with our modeling predictions (Fig. $8 B, C$ ) and suggests that vestibular inhibitory interneurons are tonic $2^{\circ} \mathrm{VNs}$, which are equivalent to mammalian type A MVN neurons (Straka et al., 2005). Thus, a conserved intrinsic vestibular circuitry exists that allows a continuous fine tuning of the response dynamics in a particular type of $2^{\circ} \mathrm{VNs}$ (Minor and Goldberg, 1991; Straka and Dieringer, 1996).

In all vertebrates, a subpopulation of central vestibular neurons receives a Purkinje cell-mediated GABAergic inhibition (Straka and Dieringer, 2004). Although this inhibition seems to be weak in frog (Magherini et al., 1975; Dieringer and Precht, 1979), a cerebellar lesion increased the gain of the abducens motoneuronal discharge during sinusoidal head rotation by $\sim 50 \%$ (Straka and Dieringer, 2004). This complies with the increase of semicircular canal nerve-evoked compound response amplitudes in phasic $2^{\circ} \mathrm{VNs}$ after a block of the cerebellar circuit (Fig. $6 \mathrm{E}$ ). The presence of a cerebellar inhibition in some phasic $2^{\circ} \mathrm{VNs}$ makes these neurons equivalent to mammalian floccular target neurons (FTN) in the MVN (De Zeeuw et al., 1994; Lisberger, 1998). In rodents, these neurons were shown to form a specific subpopulation of type B MVN neurons (Babalian and Vidal, 2000; Sekirnjak et al., 2003). Thus, a differentially organized Purkinje cell-mediated inhibition in equivalent subpopulations of vestibular neurons seems to be another conserved feature of vertebrate vestibular signal processing. The particular role of mammalian FTN in VOR plasticity and the flexibly controlled synaptic signal processing in frog phasic $2^{\circ} \mathrm{VNs}$ suggests that these neurons are part of a modifiable pathway that enables plastic adaptations of vestibulomotor responses (Lisberger, 1998; Minor et al., 1999; Boyden et al., 2004; Gittis and du Lac, 2006; Ramachandran and Lisberger, 2006, 2008).

\section{References}

Babalian A, Vibert N, Assie G, Serafin M, Mühlethaler M, Vidal PP (1997) Central vestibular networks in the guinea-pig: functional characterization in the isolated whole brain in vitro. Neuroscience 81:405-426.

Babalian AL, Vidal PP (2000) Floccular modulation of vestibuloocular pathways and cerebellum-related plasticity: an in vitro whole brain study. J Neurophysiol 84:2514-2528.

Bagnall MW, Stevens RJ, du Lac S (2007) Transgenic mouse lines subdivide medial vestibular nucleus neurons into discrete, neurochemically distinct populations. J Neurosci 28:2318-2330.

Baird RA (1994a) Comparative transduction mechanisms of hair cells in the bullfrog utriculus. I. Responses to intracellular current. J Neurophysiol 71:666-684.

Baird RA (1994b) Comparative transduction mechanisms of hair cells in the 
bullfrog utriculus. II. Sensitivity and response dynamics to hair bundle displacement. J Neurophysiol 71:685-705.

Bekkers JM, Delaney AJ (2001) Modulation of excitability by alphadendrotoxin-sensitive potassium channels in neocortical pyramidal neurons. J Neurosci 21:6553-6560.

Beraneck M, Pfanzelt S, Vassias I, Rohregger M, Vibert N, Vidal PP, Moore LE, Straka H (2007) Differential intrinsic response dynamics determine synaptic signal processing in frog vestibular neurons. J Neurosci 27:4283-4296.

BiesdorfS, Straka H (2004) Control of responses in frog second-order semicircular canal neurons by inhibitory and excitatory inputs. Soc Neurosci Abstr 30:652.1.

Biesdorf S, Malinvaud D, Reichenberger I, Pfanzelt S, Straka H (2008) Differential inhibitory control of semicircular canal nerve afferent-evoked inputs in second-order vestibular neurons by glycinergic and GABAergic circuits. J Neurophysiol 99:1758-1769.

Birinyi A, Straka H, Matesz C, Dieringer N (2001) Location of dye-coupled second order and of efferent vestibular neurons labeled from individual semicircular canal or otolith organs in the frog. Brain Res 921:44-59.

Blanks RH, Precht W (1976) Functional characterization of primary vestibular afferents in the frog. Exp Brain Res 25:369-390.

Borg-Graham L (1991) Modelling the non-linear conductances of excitable membranes. In: Cellular neurobiology: a practical approach (Chad J, Wheal H, eds). Oxford: IRL at Oxford UP.

Boyden ES, Katoh A, Raymond JL (2004) Cerebellum-dependent learning: the role of multiple plasticity mechanisms. Annu Rev Neurosci 27:581-609.

Büttner-Ennever JA (2005) The extraocular motor nuclei: organization and functional neuroanatomy. Prog Brain Res 151:95-125.

Camp AJ, Callister RJ, Brichta AM (2006) Inhibitory synaptic transmission differs in mouse type A and B medial vestibular nucleus neurons in vitro. J Neurophysiol 95:3208-3218.

Carnevale NT, Hines ML (2006) The NEURON book. Cambridge, UK: Cambridge UP.

Clendaniel RA, Lasker DM, Minor LB (2002) Differential adaptation of the linear and nonlinear components of the horizontal vestibuloocular reflex in squirrel monkeys. J Neurophysiol 88:3534-3540.

De Zeeuw CI, Wylie DR, DiGiorgi PL, Simpson JI (1994) Projections of individual Purkinje cells of identified zones in the flocculus to the vestibular and cerebellar nuclei in the rabbit. J Comp Neurol 349:428-447.

Dieringer N (1987) The role of compensatory eye and head movements for gaze stabilization in the unrestrained frog. Brain Res 404:33-38.

Dieringer N, Precht W (1977) Modification of synaptic input following unilateral labyrinthectomy. Nature 269:431-433.

Dieringer N, Precht W (1979) Mechanisms of compensation for vestibular deficits in the frog. II. Modification of the inhibitory pathways. Exp Brain Res 36:329-357.

Dieringer N, Precht W (1986) Functional organization of eye velocity and eye position signals in abducens motoneurons of the frog. J Comp Physiol 158:179-194.

du Lac S, Lisberger SG (1995) Cellular processing of temporal information in medial vestibular nucleus neurons. J Neurosci 15:8000-8010.

Eatock RA, Rüsch A, Lysakowski A, Saeki M (1998) Hair cells in mammalian utricles. Otolaryngol Head Neck Surg 119:172-181.

Gittis AH, du Lac S (2006) Intrinsic and synaptic plasticity in the vestibular system. Curr Opin Neurobiol 16:385-390.

Gittis AH, du Lac S (2007) Firing properties of GABAergic versus nonGABAergic vestibular nucleus neurons conferred by a differential balance of potassium currents. J Neurophysiol 97:3986-3996.

Gittis AH, du Lac S (2008) Similar properties of transient, persistent, and resurgent Na currents in GABAergic and non-GABAergic vestibular nucleus neurons. J Neurophysiol 99:2060-2065.

Goldberg JM (2000) Afferent diversity and the organization of central vestibular pathways. Exp Brain Res 130:277-297.

Hille B (2001) Ion channels of excitable membranes, Ed 3. Sunderland, MA: Sinauer.

Hjelmstad GO, Nicoll RA, Malenka RC (1997) Synaptic refractory period provides a measure of probability of release in the hippocampus. Neuron 19:1309-1918.

Hospedales TM, van Rossum MC, Graham BP, Dutia MB (2008) Implications of noise and neural heterogeneity for vestibulo-ocular reflex fidelity. Neural Comput 20:756-778.

Johnston D, Wu SM (1994) Foundations of cellular neurophysiology (Bradford Books). Cambridge, MA: MIT.
Johnston AR, MacLeod NK, Dutia MB (1994) Ionic conductances contributing to spike repolarization and after-potentials in rat medial vestibular nucleus neurones. J Physiol 481:61-77.

Lasker DM, Hullar TE, Minor LB (2000) Horizontal vestibuloocular reflex evoked by high-acceleration rotations in the squirrel monkey. III. Responses after labyrinthectomy. J Neurophysiol 83:2482-2496.

Lisberger SG (1998) Physiologic basis for motor learning in the vestibuloocular reflex. Otolaryngol Head Neck Surg 119:43-48.

Lisberger SG, Miles FA, Optican LM (1983) Frequency-selective adaptation: evidence for channels in the vestibulo-ocular reflex? J Neurosci 3:1234-1244

Magherini PC, Giretti ML, Precht W (1975) Cerebellar control of vestibular neurons of the frog. Pflugers Arch 356:99-109.

Minor LB, Goldberg JM (1991) Vestibular nerve inputs to the vestibuloocular reflex: a functional ablation study in the squirrel monkey. J Neurosci 11:1636-1648.

Minor LB, Lasker DM, Backous DD, Hullar TE (1999) Horizontal vestibuloocular reflex evoked by high-acceleration rotations in the squirrel monkey. I. Normal responses. J Neurophysiol 82:1254-1270.

Moore LE, Buchanan JT, Murphey CR (1995) Localization and interaction of $\mathrm{N}$-methyl-D-aspartate and non-N-methyl-D-aspartate receptors of lamprey spinal neurons. Biophys J 68:96-103.

Murphey CR, Moore LE, Buchanan JT (1995) Quantitative analysis of electrotonic structure and membrane properties of NMDA-activated lamprey spinal neurons. Neural Comp 7:486-506.

Peusner KD, Giaume C (1997) Ontogeny of electrophysiological properties and dendritic pattern in second-order chick vestibular neurons. J Comp Neurol 384:621-633.

Pfanzelt S, Rohregger M, Moore LE, Straka H (2004) Differential dynamics of labyrinthine nerve afferent-evoked responses in tonic and phasic frog second-order vestibular neurons. Soc Neurosci Abstr 30:652.2.

Ramachandran R, Lisberger SG (2006) Transformation of vestibular signals into motor commands in the vestibuloocular reflex pathways of monkeys. J Neurophysiol 96:1061-1074.

Ramachandran R, Lisberger SG (2008) Neural substrate of modified and unmodified pathways for learning in monkey vestibulo-ocular reflex. J Neurophysiol, in press.

Saint Mleux B, Moore LE (2000) Active dendritic membrane properties of Xenopus larval spinal neurons analyzed with a whole cell soma voltage clamp. J Neurophysiol 83:1381-1393.

Sekirnjak C, Vissel B, Bollinger J, Faulstich M, du LacS (2003) Purkinje cell synapses target physiologically unique brainstem neurons. J Neurosci 23:6392-6398.

Serafin M, de Waele C, Khateb A, Vidal PP, Mühlethaler M (1991) Medial vestibular nucleus in the guinea-pig. I. Intrinsic membrane properties in brainstem slices. Exp Brain Res 84:417-425.

Shimazu H, Precht W (1965) Tonic and kinetic responses of cat's vestibular neurons to horizontal angular acceleration. J Neurophysiol 28:991-1013.

Spencer RF, Porter JD (2005) Biological organization of the extraocular muscles. Prog Brain Res 151:43-80.

Straka H, Dieringer N (1991) Internuclear neurons in the ocular motor system of frogs. J Comp Neurol 312:537-548.

Straka H, Dieringer N (1993) Electrophysiological and pharmacological characterization of vestibular inputs to identified frog abducens motoneurons and internuclear neurons in vitro. Eur J Neurosci 5:251-260.

Straka H, Dieringer N (1996) Uncrossed disynaptic inhibition of second-order vestibular neurons and its interaction with monosynaptic excitation from vestibular nerve afferent fibers in the frog. J Neurophysiol 76:3087-3101.

Straka H, Dieringer N (2000) Convergence pattern of uncrossed excitatory and inhibitory semicircular canal-specific inputs onto second-order vestibular neurons of frogs. Exp Brain Res 135:462-473.

Straka H, Dieringer N (2004) Basic organization principles of the VOR: lessons from frogs. Prog Neurobiol 73:259-309.

Straka H, Biesdorf S, Dieringer N (1997) Canal-specific excitation and inhibition of frog second order vestibular neurons. J Neurophysiol 78:1363-1372.

Straka H, Holler S, Goto F (2002) Patterns of canal and otolith afferent input convergence in frog second order vestibular neurons. J Neurophysiol 88:2287-2301.

Straka H, Beraneck M, Rohregger M, Moore LE, Vidal PP, Vibert N (2004) Second-order vestibular neurons form separate populations with different membrane and discharge properties. J Neurophysiol 92:845-861.

Straka H, Vibert N, Vidal PP, Moore LE, Dutia MB (2005) Intrinsic membrane properties of vertebrate vestibular neurons: function, development and plasticity. Prog Neurobiol 76:349-392. 